\title{
Desigualdade e Discriminação de Imigrantes Internacionais no Mercado de Trabalho Brasileiro*
}

\author{
Elaine Meire Vilela
}

Doutora em Ciências Humanas (Sociologia) pela Universidade Federal de Minas Gerais (UFMG), professora adjunta do Departamento de Sociologia e Antropologia da mesma universidade e vice-coordenadora do Laboratório de Pesquisa em Estratificação Social e Trabalho (LAPEST-UFMG). Belo Horizonte, MG, Brasil. E-mail: emvilela@gmail.com

\section{INTRODUÇÃO}

$\mathrm{M}$ uitos estudos verificam que há desigualdades de posição ocupacional e rendimentos dos imigrantes internacionais no mercado de trabalho da sociedade hospedeira, comparados aos nativos (Bonacich, 1973; Piore, 1979; Portes e Bach, 1985; Jong e Madamba, 2001; Van Tubergen, Maas e Flap, 2004; Sala, 2005; Van Tubergen, 2005; Piore e Safford, 2007; Vilela, 2008; Kesler e Hout, 2010). Alguns afirmam que os imigrantes estão em pior situação no mercado de trabalho e são discriminados negativamente, dada a sua inserção em trabalhos precários no setor periférico do mercado de trabalho segmentado (por exemplo, Piore, 1979). Há quem sugira que eles permanecem em posições polarizadas, isto é, tanto no topo quanto na base da hierarquia socioeconômica ocupacional, tomando como fundamento a teoria do mercado dual (Sassen, 1990). Por fim, há outros que argumentam que diversos grupos de imigrantes se encontram em posições intermediárias ou superiores e são discriminados positivamente, uma vez que se

\footnotetext{
* Esse artigo resume alguns temas desenvolvidos em minha tese de doutorado, defendida na Faculdade de Filosofia e Ciências Humanas (Fafich), da Universidade Federal de Minas Gerais, em 2008. Agradeço aqui pelos comentários e sugestões da banca de defesa, em especial, de meu orientador, Jorge Alexandre Barbosa Neves, e do professor Nelson do Valle Silva. Agradeço, também, a Pedro Robson Neiva e Izabel Cristina Vilela Santos pelas valiosas contribuições para a finalização desse estudo.
}

DADOS - Revista de Ciências Sociais, Rio de Janeiro, vol. 54, n- 1, 2011, pp. 89 a 128. 
inserem em um mercado de trabalho paralelo ao mercado aberto e competitivo, em uma economia étnica (por exemplo, Bonacich, 1973; Portes e Bach, 1985; Portes e Rumbaut, 1990).

Segundo Van Tubergen, Maas e Flap (2004) e Kesler e Hout (2010), a explicação para a localização dos imigrantes na estrutura hierárquica do mercado de trabalho depende tanto de fatores individuais quanto estruturais. No primeiro grupo, incluem-se informações relacionadas principalmente ao capital humano ${ }^{1}$; no segundo, encontram-se elementos referentes à origem e ao destino dos trabalhadores. Os autores afirmam que, dadas as diferenças em tais fatores, não há uma homogeneização quanto à inserção e à situação dos imigrantes no mercado de trabalho. Segundo Borjas (1986), a explicação encontra-se principalmente na discriminação, pela qual os empregadores ${ }^{2}$ levam em consideração atributos não produtivos, como raça, gênero e origem nacional, no momento de realizarem as trocas de salário por produto.

Os estudos que comparam grupos de múltiplas origens, que se localizam em um destino comum, como no caso dessa pesquisa, verificam que há diferença na posição econômica entre os imigrantes de grupos de origens diferentes, mesmo depois de controladas as características referentes aos atributos produtivos individuais e ao local de destino (Van Tubergen, Maas e Flap, 2004). Em outras palavras, há grupos de imigrantes que se encontram em situação econômica privilegiada na sociedade hospedeira e outros que, ao contrário, estão em condições precárias. De acordo com Van Tubergen, Maas e Flap (2004), esse resultado foi observado nos Estados Unidos, Canadá, Bélgica, Alemanha, França e Israel, sendo a origem um fator de impacto, ora positivo, ora negativo, dependendo do grupo em análise. Por outro lado, pesquisas não encontraram diferenças significativas entre imigrantes de mesma origem que se dirigiram para destinos diferentes (Van Tubergen, Maas e Flap, 2004). Tais achados sugerem um impacto maior da origem do que do destino sobre a situação dos imigrantes no mercado de trabalho na sociedade anfitriã.

A minha proposta neste artigo é trazer esse debate para o Brasil. Entre outras, pretendo responder às seguintes perguntas: comparados aos brasileiros, os imigrantes internacionais encontram-se em posições piores, melhores ou similares no mercado de trabalho? Quais imigrantes se encontram em desvantagem, quais estão em vantagem? Eles recebem rendimentos menores ou maiores do que os nativos? Os imigran- 
tes internacionais são discriminados? Quais deles? A discriminação é positiva ou negativa?

Na seção que se segue, faço uma revisão da literatura que trata do tema, explorando as principais divergências nas três abordagens que estão sendo aqui consideradas. Em seguida, na terceira seção, apresento os dados e as técnicas estatísticas empregadas. Na quarta seção, parto para a análise efetiva dos dados, mostrando os resultados encontrados quanto às desigualdades de posições de classes e de rendimentos, bem como realizo a análise da discriminação. Por fim, teço algumas observações a título de conclusão.

\section{ABORDAGENS TEÓRICAS}

O debate sobre a situação dos imigrantes no mercado de trabalho apresenta três abordagens diferentes. A primeira refere-se à ideia de que há um mercado aberto e dual ${ }^{3}$, segmentado por ocupações de prestígio (setor de empregos primário) e precárias (setor de empregos secundário $)^{4}$ (Piore, 1979; Piore e Sabel, 1984; Piore e Safford, 2007). De acordo com essa abordagem, os imigrantes inserem-se no segundo setor, estando em desvantagem no que diz respeito a rendimentos e a status socioeconômico ocupacional.

No primeiro, encontram-se empregos estáveis, seguros, trabalhadores qualificados, bem remunerados, com boas condições de trabalho e com possibilidade de mobilidade ascendente. Nele, há o predomínio de profissionais com maior conhecimento e mais experiência, mais educados e profissionalizados. Ao contrário, o setor secundário apresenta empregos instáveis, desqualificados, com baixos salários, benefícios limitados, condições insatisfatórias de trabalho e baixa mobilidade (Piore, 1979; Piore e Sabel, 1984; Piore e Safford, 2007). Esse setor não oferece grandes oportunidades para ascensão nos postos de trabalho. Segundo Dickens e Lang (1985), há barreiras não econômicas que impedem que os trabalhadores desse setor mudem para o primeiro. Além disso, o setor secundário proporciona baixíssimo retorno salarial, em consequência da educação baixa e da falta de treinamento para os empregados (Dickens e Lang, 1985).

Em função de tais condições, existe uma menor demanda pelos empregos no segundo setor. De acordo com Piore (1979) e Massey et alii (1993), os nativos os rejeitam, abrindo espaço para os imigrantes, que encontram dificuldade de inserção em melhores posições ocupacio- 
nais no país hospedeiro, considerando que: a) entre eles, há uma minoria de pessoas altamente qualificadas (Piore, 1979); b) a maioria dos imigrantes origina-se de países pobres, os quais não propiciam condições para que seus nativos tenham um maior nível de capital humano; c) o capital humano obtido no país de origem, com poucas exceções, é menos valorizado do que a educação e a experiência adquiridas na sociedade anfitriã, além de ser difícil a transferência de habilidades para o sistema imposto pela sociedade hospedeira (Friedberg, 2000; Zeng e Xie, 2004); d) por acreditar ser temporária a sua permanência no local de destino, a maioria dos imigrantes aceita os serviços e as condições de trabalho do segundo setor no mercado de trabalho, desde que venha a ganhar dinheiro para melhorar seu bem-estar no local de origem (Piore, 1979; Massey et alii, 1993); e) os empregadores discriminam grupos de imigrantes, dependendo da nacionalidade (Piore, 1979).

É importante ressaltar que, para os teóricos do mercado segmentado, o diferencial de rendimentos entre imigrantes e nativos é fruto do próprio mercado e não de características produtivas dos indivíduos, como o capital humano. A discriminação seria o motivo para a persistência desse efeito estrutural sobre os salários e para a limitação da mobilidade dos indivíduos entre os postos de trabalho, o que evidencia a imperfeição do mercado.

A segunda abordagem, sobre a situação dos imigrantes no mercado de trabalho, fundamenta-se nas ideias de Sassen (1990; 1998), que argumenta haver grupos de imigrantes em vantagem, bem como aqueles que se encontram em desvantagem no mercado de trabalho. De fato, de acordo com a autora, existe sim um mercado segmentado entre o primeiro e o segundo setores. Porém os imigrantes tendem a se inserir nos extremos da estrutura ocupacional, isto é, em ocupações de qualificação muito alta ou muito baixa, muito bem ou muito mal remuneradas, estáveis ou instáveis. Isto porque, devido à reorganização da economia mundial, criou-se um espaço transnacional, no qual circulam não apenas mercadorias, serviços e informações, mas também trabalhadores altamente qualificados e outros desqualificados. Além disso, a autora acrescenta que não apenas os países menos desenvolvidos enviam imigrantes, mas também os mais desenvolvidos (cf. também Portes, 1995).

A terceira abordagem sugere a existência de um mercado paralelo ao mercado dual, que protege muitos imigrantes de competirem com os nativos no mercado aberto da sociedade hospedeira. Para os estudio- 
sos dessa corrente, os imigrantes também inserem-se em ocupações intermediárias ou superiores às dos nativos (Bonacich, 1973; Portes e Bach, 1985; Light et alii, 1994).

Segundo Bonacich (1973), diversos grupos de imigrantes, ao fixarem residência na sociedade de destino, ocupam mais as posições intermediárias na hierarquia ocupacional do que as de baixo escalão. A autora afirma que determinados grupos de imigrantes tendem a se concentrar em certas ocupações, principalmente na área do comércio, cumprindo uma função de intermediários entre produtores e consumidores, empregadores e empregados, elite e massa, que lhes proporcionam mobilidade ascendente na hierarquia socioeconômica e ocupacional no local de destino. Além disso, os imigrantes buscam ocupações flexíveis, autônomas, que não estabelecem vínculos empregatícios formais no mercado aberto, facilitando assim o retorno à terra natal.

Para Portes e Bach (1985), bem como para Light et alii (1994; 1995), firmas e setores étnicos empregadores de imigrantes coexistem com as outras firmas no mercado, permitindo uma situação privilegiada dos imigrantes no mercado de trabalho, na maioria dos casos. Essa vantagem é válida tanto para os rendimentos quanto para o status ocupacional (Bonacich, 1973; Portes e Bach, 1985; Light et alii, 1994). Nas empresas de enclave étnico ${ }^{5}$, os cargos de direção são ocupados pelos compatriotas do empregador e as posições de mais baixo escalão costumam ser preenchidas pelos nativos ou pelos membros de outros grupos étnicos.

Estudos recentes não partem diretamente da ideia de mercado aberto ou paralelo (Van Tubergen, Maas e Flap, 2004; Kesler e Hout, 2010), porque a realidade atual é bem diferente daquela em que as abordagens acima floresceram (décadas de 1970 e de 1980). Atualmente, os países desenvolvidos e os em desenvolvimento experimentam um processo de informalização, que provoca transformações no mundo do trabalho, a saber: tendência geral à terceirização; elevação das taxas de desemprego; precarização do emprego assalariado (Guimarães, 2009; Rivero, 2009).

Tais estudos demonstram que fatores macro, tais como as regiões de destino e de origem da migração, além das características individuais dos imigrantes, devem ser considerados para se compreender melhor a situação dos imigrantes no mercado de trabalho da sociedade hospedeira (Van Tubergen, Maas e Flap, 2004; Kesler e Hout, 2010). Pesqui- 
sas em diversos países identificam que a origem do imigrante afeta a sua inserção no mercado de trabalho. Ou seja, quando se analisam diversos grupos de imigrantes de origens diferentes com um destino semelhante, observa-se que, após controladas as características dos indivíduos e do local de destino, bem como a situação do mercado, a origem mantém alta correlação com a localização do indivíduo na estrutura hierárquica socioeconômica. Em outras palavras, alguns grupos de imigrantes encontram-se em vantagem e outros em desvantagem, dependendo do grupo de origem, mantendo todo o resto constante (Van Tubergen, Maas e Flap, 2004).

Pesquisas mostram evidências de que o "negócio étnico" é considerado uma forma de concentração dos trabalhadores imigrantes, bem como uma rota de mobilidade social para os mesmos (Portes e Jensen, 1989; Halter, 2007; Kesler e Hout, 2010). Kesler e Hout (2010) chamam atenção para a não-homogeneidade nas taxas de empreendedorismo étnico e o negócio próprio entre os imigrantes. Além disso, ressaltam que tais economias étnicas são marcas de sucesso para alguns, mas podem não passar de um modo de sobrevivência, ou de uma situação temporária, para outros. Mais uma vez, o sucesso ou o fracasso estão correlacionados com a origem dos imigrantes.

Em suma, todos esses estudos buscam compreender se os imigrantes se encontram em situação diferente das vivenciadas pelos nativos, especialmente no que diz respeito ao mercado de trabalho. Seus achados são de que há sim diferenças entre esses grupos na estrutura hierárquica do trabalho, não havendo homogeneização e uma situação generalizante para todos os grupos de imigrantes étnicos/nacionais. Pelo contrário, o traço marcante é a heterogeneidade. Alguns encontram-se em vantagem e outros em desvantagem, dependendo mais de suas origens do que de seus destinos. Outro resultado é o de que, em geral, os nativos pertencentes a grupos minoritários, tais como mulheres e negros, estão em situação similar ou pior no mundo do trabalho, em comparação com alguns grupos étnicos/nacionais. Por fim, os achados são de que o status de migrante, majoritariamente, gera vantagem no mercado de trabalho (Jong e Madamba, 2001; Van Tubergen, Maas e Flap, 2004; Kesler e Hout, 2010).

Esses temas são considerados importantes nos países desenvolvidos, especialmente nos Estados Unidos, para onde se destina um fluxo migratório intenso. No Brasil, eles não receberam muita atenção das áreas 
que tratam de estratificação social e de migração internacional, embora haja exceções (Sala, 2005; Silva, 2006; Vilela, 2008). Provavelmente, a situação decorre do baixo número de imigrantes internacionais que se dirigem para o país, vis-à-vis os que se encontram nas economias mais desenvolvidas. Porém o tema da imigração internacional deve receber melhor atenção dos estudiosos e dos elaboradores de políticas públicas, dado o papel que os imigrantes tiveram nas histórias antiga e recente do país. Mais ainda, se considerarmos o surto de desenvolvimento econômico que o Brasil vem experimentando, que deverá fazer com que aumente o fluxo desses trabalhadores para o nosso mercado. Essa pesquisa busca ajudar a preencher essa lacuna, verificando a situação dos imigrantes no mercado de trabalho brasileiro.

\section{OS DADOS E OS MODELOS DE ANÁLISE}

Para realizar a pesquisa, utilizo os dados de uma subamostra do Censo Demográfico Brasileiro de 2000. Embora não seja a fonte de informação mais recente, dois motivos principais justificam a minha escolha: $o$ primeiro é que ela permite identificar e classificar a nacionalidade dos imigrantes internacionais. Isso não seria possível a partir da Pesquisa de Emprego e Desemprego (PED) e da Pesquisa Nacional por Amostra de Domicílios (PNAD), as quais agregam todos os imigrantes na categoria "outros países". O segundo motivo é que o Censo contém uma amostra representativa desses imigrantes no Brasil, o que não é oferecido pelos dois bancos de dados mencionados.

É importante dizer que os dados censitários sobre imigração internacional são subestimados, já que há um grande número de imigrantes vivendo no Brasil de forma clandestina e que, por esse motivo, não são computados pelo Censo Demográfico oficial. Os números sobre tais imigrantes ilegais são desconhecidos; sabe-se, porém, que o de latino-americanos é bem maior do que os apresentados pelas estimativas e levantamentos oficiais (Silva, 1998; 2006; Ântico, 1998; Martes, 2009) ${ }^{6}$. Portanto, os resultados mostrados aqui são limitados, uma vez que se referem aos imigrantes legais.

Esse estudo trabalha com oito grupos de imigrantes ${ }^{7}$ internacionais, a saber: argentinos, bolivianos, chilenos, paraguaios, peruanos, uruguaios, chineses ${ }^{8}$ e coreanos ${ }^{9}$. A seleção de tais grupos deve-se a algumas características específicas, tais como: residência no Brasil a partir da década de 1970, momento que marca o início de um novo período 
migratório no país; origem em países em desenvolvimento; contingente mínimo de $1 \%$ do total de imigrantes internacionais residentes no país, patamar adotado para que se possa tratar estatisticamente os dados.

Os imigrantes são comparados com os brasileiros natos, tanto os migrantes quanto os não migrantes ${ }^{10}$. O primeiro grupo representa as pessoas que não residiam no mesmo estado de nascimento ${ }^{11}$ na data do Censo (2000); o segundo refere-se aos que moravam no estado natal. Essa divisão entre os brasileiros fundamenta-se no pressuposto de que as pessoas que migram têm características próprias que as diferem dos não migrantes. Estou falando da "autosseletividade positiva", isto é, da ideia de que migrantes teriam características diferenciadoras; em geral, seriam pessoas mais ambiciosas, criativas, trabalhadoras, competitivas, jovens e educadas do que indivíduos que escolhem permanecer em seus lugares de origem ${ }^{12}$, como sugerem os estudos de Chiswick (1999), Zavodny (2003), Aydemir (2003) e Golgher (2006). No Brasil, Santos Júnior e colaboradores (2005) verificaram que os homens migrantes internos são positivamente selecionados, tanto em relação à população de origem quanto à de destino.

A partir dessa ideia, pressuponho que os brasileiros migrantes internos são, em geral, diferentes dos brasileiros não migrantes, aproximando-se das características dos imigrantes internacionais. Dessa forma, infiro que as diferenças entre os imigrantes internacionais e os brasileiros não migrantes sejam maiores do que as diferenças entre eles e os brasileiros migrantes, tanto no que se refere às características pessoais quanto em relação à situação no mercado de trabalho, o que supostamente acarretaria diferenças em termos de rendimentos e de status socioeconômico ocupacional.

A análise é segmentada também de acordo com a idade e o sexo. Devido ao meu interesse em aspectos referentes ao mercado de trabalho (segregação ocupacional e rendimento) e, a despeito das diversidades de inserção no mercado de trabalho entre homens e mulheres (Soares, 2000; Gomes e Wajnman, 2005) ${ }^{13}$, analiso apenas os homens em idade economicamente ativa (ocupados e desocupados), entre 25 e 60 anos de idade. A idade mínima de 25 anos foi definida porque, em geral, pessoas nessa faixa etária têm grande probabilidade de já terem concluído seus estudos, estando mais propensas a estar inseridas no mer- 
cado de trabalho ${ }^{14}$; a idade máxima de 60 anos deve-se ao fato de ser esta a idade de aposentadoria dos homens no Brasil no ano de 2000.

Para a análise dos dados, utilizo três técnicas estatísticas diferentes: Modelo Heckman, Regressão Logística Multinomial e Decomposição de Oaxaca. A primeira permite apresentar os estimadores de uma regressão linear múltipla, além de possibilitar o controle de um eventual viés de seleção na amostra. No caso da presente pesquisa, o viés poderia ocorrer caso fossem incluídos na amostra apenas os indivíduos que trabalham, deixando de fora os que não trabalham. De acordo com Heckman (1979), pessoas que estão fora do mercado de trabalho têm motivos não observados que, indiretamente, podem influenciar os salários daquelas que estão empregadas. Desta forma, foram incluídos tanto os ocupados quanto os desocupados, conforme sugere o modelo de regressão criado por Heckman, que verifica se existe eventual viés de seleção, corrigindo-o em caso afirmativo.

Em um modelo desse tipo, existem duas regressões simultâneas: uma logit, referente à variável dependente binária, que controla as informações relacionadas ao fato do indivíduo estar ou não empregado; e outra linear, relativa à variável dependente contínua, que constitui a resposta que quero avaliar efetivamente. Para o cálculo dessa última, utilizo o logaritmo natural de rendimentos mensais em todos os trabalhos executados: $\ln (S)$ i (Salário/mês). Na aplicação do modelo logit, utilizo a variável Trabremun, que é apresentada na forma binária: ocupados são codificados como 1 ; desocupados ou inativos, como 0 . No procedimento proposto por Heckman, essa é a variável que testa se a seleção na amostra é enviesada e possibilita o seu controle, em caso afirmativo.

Embora a regressão logística do Heckman seja importante para o cálculo dos estimadores de rendimentos dos imigrantes e dos brasileiros, os seus resultados não são apresentados no texto, como forma de poupar o leitor de um excesso de números. Portanto, apenas os estimadores da equação linear são analisados no decorrer do trabalho. A seguir, apresento o modelo:

$$
\begin{aligned}
& \gamma=\ln (S)_{i}=\beta_{0}+\beta_{1} \text { Origem }+\beta_{2} \text { Educ }+\beta_{3} \text { Exp }+\beta_{4} \text { Exp }{ }^{2}+\beta_{5} \text { Região }+ \\
& \beta_{6} \text { Urbano }+\beta_{7} \text { Branca }+\beta_{8} \text { Estado civil }+\beta_{9} \text { Posidom }+\beta_{10} \text { Ter Relig } \\
& \beta_{11} \text { Posição de classe }+\beta_{12} \text { Horas }+\beta_{13} \text { Quant Trab, select }=\text { trabremun }=\beta_{0}+\beta_{1} \\
& \text { Origem }+\beta_{2} \text { Educ }+\beta_{3} \text { Exp }+\beta_{4} \text { Exp }{ }^{2}+\beta_{5} \text { Região }+\beta_{6} \text { Urbano }+\beta_{7} \text { Branca }+ \\
& \beta_{8} \text { Estado civil }+\beta_{9} \text { Posidom }+\beta_{10} \text { Ter Relig }+\varepsilon
\end{aligned}
$$


Onde,

$\ln (S)_{i}$ é o logaritmo natural de rendimentos em todos os trabalhos do indivíduo $i$;

Trabremun é a variável de controle de viés de seleção;

$\beta_{0}$, a constante;

$\beta_{1,2 \ldots 13}$ os estimadores das seguintes variáveis explicativas:

a) $\beta_{1}$ - origem: variável indicadora dos grupos étnicos/nacionais, que agrega nove variáveis binárias - os brasileiros não migrantes ou os brasileiros migrantes (categorias de referência), os argentinos, os bolivianos, os chilenos, os paraguaios, os peruanos, os uruguaios, os chineses e os coreanos. Trata-se de variável explicativa fundamental, principal foco da presente análise.

b) $\beta_{1,2 \ldots 13}$ - Educação $(E d u c)$; experiência $(E x p)$; experiência ao quadrado (Exp²); cor branca; ter religião (TerRelig); estado civil (casado, separado, viúvo); posição no domicílio (Posdom; cônjuge, filho ou outra posição); região (Nordeste, Norte, Sul e Centro-Oeste); urbano; horas; e quantidade de trabalho (QuantTrab). A descrição dessas variáveis e suas respectivas medidas podem ser vistas no Apêndice ${ }^{15}$. Ressalto que os asiáticos são comparados apenas com os brasileiros brancos. Não faria muito sentido comparar coreanos e chineses, cuja população é quase $100 \%$ branca, com brasileiros não brancos, por essa ser uma comparação entre grupos heterogêneos.

$\varepsilon$ é o termo referente ao erro.

A segunda técnica de análise permite mensurar o status sócio-ocupacional dos grupos de indivíduos. O modelo logístico multinomial parece ser o mais apropriado para essa situação, já que a variável resposta contém mais de duas categorias. Seja $Y_{i}$ uma variável resposta aleatória categórica, consequentemente $Y_{i}=1,2 \ldots J$ categorias. Para descrever a distribuição de probabilidade de $Y_{i}$, faz-se necessário definir um vetor aleatório. No caso desse estudo, o $Y_{i}$ é posição de classe ${ }^{16}$ composta por quatro categorias, sendo: a) classe 1: profissionais, administradores, trabalhadores não manuais de alto nível e pequenos proprietários empregadores (categoria de referência); b) classe 2: pequenos proprietários e conta-própria, técnicos e supervisores do trabalho manual, trabalhadores não manuais de baixo nível, trabalhadores manuais quali- 
ficados e pequenos empregadores rurais; c) classe 3: trabalhadores manuais semiqualificados e não qualificados e os trabalhadores rurais; d) classe 4: desocupados e inativos ${ }^{17}$. Tais categorias podem ser visualizadas no Quadro 1.

\section{Quadro 1}

Posição de Classe, Hierarquia, Relações de Emprego e Ocupações

\begin{tabular}{|c|c|c|c|c|c|}
\hline $\begin{array}{c}\text { Posição de } \\
\text { Classe }\end{array}$ & $\begin{array}{c}\text { Hierarquia } \\
\text { Estratos }\end{array}$ & Classes sociais & & $\begin{array}{l}\text { Regulamentação } \\
\text { do emprego }\end{array}$ & $\begin{array}{l}\text { Exemplos de } \\
\text { ocupações }\end{array}$ \\
\hline $1^{a}$ & $1^{\circ}$ & $\begin{array}{l}\text { Trabalho não manual } \\
\text { urbano } \\
\text { Profissional e } \\
\text { administradores de } \\
\text { nível alto }\end{array}$ & I & $\begin{array}{l}\text { Trabalho com } \\
\text { autonomia e } \\
\text { autoridade }\end{array}$ & $\begin{array}{l}\text { Juiz, diretor de } \\
\text { empresas, } \\
\text { consultor }\end{array}$ \\
\hline $1^{\mathrm{a}}$ & $2^{\circ}$ & $\begin{array}{l}\text { Profissionais e } \\
\text { administradores de } \\
\text { nível baixo }\end{array}$ & II & & Contador, gerente \\
\hline $1^{\mathrm{a}}$ & $2^{\circ}$ & $\begin{array}{l}\text { Trabalhadores não } \\
\text { manuais de rotina } \\
\text { (nível alto) }\end{array}$ & $\mathrm{III}_{\mathrm{a}}$ & $\begin{array}{l}\text { Mista } \\
\text { (supervisionado e } \\
\text { com autonomia) }\end{array}$ & $\begin{array}{l}\text { Secretário de } \\
\text { escritório, } \\
\text { escriturário }\end{array}$ \\
\hline $1^{\mathrm{a}}$ & $2^{\circ}$ & $\begin{array}{l}\text { "Pequenos" } \\
\text { proprietários, } \\
\text { empregadores }\end{array}$ & $\mathrm{IV}_{\mathrm{a}}$ & Empregador & $\begin{array}{l}\text { Dono de padaria, } \\
\text { dono de lojas }\end{array}$ \\
\hline $2^{a}$ & $3^{\circ}$ & $\begin{array}{l}\text { "Pequenos" } \\
\text { proprietários, conta } \\
\text { própria }\end{array}$ & $\mathrm{IV}_{\mathrm{b}}$ & Conta Própria & $\begin{array}{l}\text { Comerciante } \\
\text { ambulante, } \\
\text { proprietário de } \\
\text { comércio }\end{array}$ \\
\hline $2^{\mathrm{a}}$ & $4^{\circ}$ & $\begin{array}{l}\text { Trabalhadores não } \\
\text { manuais de rotina } \\
\text { (nível baixo }\end{array}$ & $\mathrm{III}_{\mathrm{b}}$ & $\begin{array}{l}\text { Trabalho } \\
\text { supervisionado }\end{array}$ & $\begin{array}{l}\text { Balconista, } \\
\text { garçom }\end{array}$ \\
\hline $2^{a}$ & $3^{\circ}$ & $\begin{array}{l}\text { Trabalho manual } \\
\text { urbano } \\
\text { Técnicos e } \\
\text { supervisores do } \\
\text { trabalho manual }\end{array}$ & V & $\begin{array}{l}\text { Mista } \\
\text { (supervisionado e } \\
\text { com autonomia) }\end{array}$ & $\begin{array}{l}\text { Técnico em } \\
\text { telecomunicações, } \\
\text { mestre de obras }\end{array}$ \\
\hline $2^{a}$ & $4^{\circ}$ & $\begin{array}{l}\text { Trabalhadores } \\
\text { manuais qualificados }\end{array}$ & VI & $\begin{array}{l}\text { Trabalho } \\
\text { supervisionado }\end{array}$ & $\begin{array}{l}\text { Mecânico de } \\
\text { automóveis }\end{array}$ \\
\hline $3^{\mathrm{a}}$ & $5^{\circ}$ & $\begin{array}{l}\text { Trabalhadores } \\
\text { manuais semi e não } \\
\text { qualificados }\end{array}$ & $\mathrm{VII}_{\mathrm{a}}$ & & $\begin{array}{l}\text { Pedreiro, porteiro, } \\
\text { pintor }\end{array}$ \\
\hline $2^{\mathrm{a}}$ & $4^{\circ}$ & $\begin{array}{l}\text { Trabalho Rural } \\
\text { Pequenos } \\
\text { empregadores rurais }\end{array}$ & $\mathrm{IV}_{\mathrm{c}}$ & Empregador & $\begin{array}{l}\text { Fazendeiro, } \\
\text { agricultor }\end{array}$ \\
\hline $3^{a}$ & $5^{\circ}$ & Trabalhadores rurais & $\mathrm{VII}_{\mathrm{b}}$ & $\begin{array}{l}\text { Trabalho } \\
\text { supervisionado }\end{array}$ & $\begin{array}{l}\text { Cortador de cana, } \\
\text { trabalhador de } \\
\text { enxada }\end{array}$ \\
\hline $4^{\mathrm{a}}$ & - & Nenhuma ocupação & - & & $\begin{array}{l}\text { Desocupado ou } \\
\text { inativo }\end{array}$ \\
\hline
\end{tabular}

Fonte: Ribeiro (2003:396), com adaptações feitas pela autora. 
Para a construção da variável "posição de classe", fundamento-me no trabalho de Ribeiro (2003), que se baseia no esquema CASMIN (Comparative Analysis of Social Mobility in Industrial Nations). Ao ser comparado com outras classificações de status ocupacional, o CASMIN apresenta a vantagem de ser semelhante ao índice criado por Nelson do Valle Silva (1988, apud Ribeiro, 2003), amplamente utilizado em estudos da área. Além disso, ele possibilita fazer comparações internacionais e admite agrupar as ocupações em posições de classes baseadas em alguma forma de hierarquia ${ }^{18}$, o que facilita as análises e as conclusões (Ribeiro, 2003).

Ao fazer a distinção de classe, a CASMIN baseia-se em quatro critérios principais. O primeiro deles refere-se às relações de emprego (proprietários - empregadores e autônomos - empregados). O segundo critério diz respeito às diferenças de contratos de trabalho (restrito - diretamente supervisionados - ou amplo - que tem autonomia e autoridade). O terceiro envolve os contrastes entre proprietários empregadores e proprietários autônomos ou por conta-própria. O quarto critério fundamenta-se nas diferenças entre trabalho não manual urbano, trabalho manual urbano e trabalho rural (Ribeiro, 2003).

É importante destacar que a variável "posição de classe" é dependente no Modelo Logístico Multinomial ${ }^{19}$, mas é independente no Modelo Heckman, que se refere a rendimento. Para o controle do viés de seleção na regressão logística multinomial, incluo a variável denominada probTrab (probabilidade de trabalhar) na equação, como propõem Jong e Madamba (2001). Ela diz respeito à probabilidade de o indivíduo estar ocupado, calculada em uma regressão logística que tem como variável dependente "Trabremun" (apresentada no Modelo Heckman). Isso é feito porque o Modelo Logístico Multinomial não permite computar simultaneamente as duas equações, como faz o Modelo Heckman. Sendo assim, a equação da segunda técnica tem o seguinte formato:

Onde $j$ representa a j-ésima categoria, 1 a categoria de referência, $P$ a probabilidade, $\beta_{0}$ é a constante, $\beta_{1,2 \ldots 11}$ os estimadores das variáveis independentes e $\varepsilon$ o erro.

A terceira técnica, o Modelo de Decomposição de Oaxaca, permite identificar a discriminação dos imigrantes internacionais no mercado de trabalho (Oaxaca, 1973; Jann, 2008). Ela é similar ao método de discriminação de média proposto por Silva $(1980 ; 1981)$, que tem a mes- 
ma função. O modelo é fruto de estimativas de regressões do tipo "Heckman" referente a rendimentos dos dois grupos que se deseja comparar, no caso: brasileiros $\left(^{b}\right)$ (sendo uma equação para brasileiros migrantes e outra para brasileiros não migrantes) e imigrantes internacionais nascidos no país j ${ }^{(i m j}$ ). Para isso, é necessário calcular uma equação de rendimentos para cada grupo separadamente e computar a decomposição de Oaxaca, a partir dos componentes não explicado (1) e explicado (2), com os seguintes formatos:

(1) $D=\left[\left(\beta_{0}^{b}+\beta_{0}^{i m j}\right)+\sum\left[\bar{x}_{i m j}\left(\beta_{k}^{b}-\beta_{k}^{i m j}\right)\right]\right.$

(2) $E=\left[\sum \beta_{b}\left(\bar{x}_{b}-\bar{x}_{i m j}\right)\right]$

Onde:

$D$ é a medida de discriminação, valor não explicado pelas variáveis incluídas nos modelos.

$\beta_{0}^{b}$ refere-se ao intercepto da equação mensurado para brasileiros (migrantes ou não migrantes).

$\beta_{0}^{i m j}$ diz respeito ao intercepto da equação calculado para os imigrantes internacionais no país $j$.

$\left(\beta_{0}^{b}-\beta_{0}^{i m j}\right)$ indica as diferenças de rendimentos entre os grupos em comparação, assumindo um mesmo valor para todas as variáveis explicativas. Uma diferença positiva no seu resultado diz o quanto os brasileiros são mais bem pagos do que o grupo de imigrantes oriundo do país $j$.

$\sum\left[\bar{x}_{i m j}\left(\beta_{k}^{b}-\beta_{k}^{i m j}\right)\right.$ significa a valorização desigual de um mesmo atributo (pessoal ou produtivo), apenas por serem de grupos diferentes. $\mathrm{O}$ cálculo é feito pelo somatório dos valores das médias das variáveis independentes $(\bar{x})$, para cada grupo de imigrante, multiplicado pela diferença entre os coeficientes dos estimadores das variáveis independentes do grupo de brasileiros $\left(\beta_{k}^{b}\right)$ e do grupo de imigrantes $\left(\beta_{k}^{i m j}\right)$. Essa equação resulta na parcela não explicada do hiato salarial, atribuíveis aos valores diferentes dados aos atributos apresentados a partir das variáveis estabelecidas no modelo. Novamente, um valor positivo indica que os atributos e as características dos brasileiros são mais valorizados do que aqueles referentes aos imigrantes originários do país $j$. 
A soma dos dois termos da equação representa a diferença dos rendimentos que não é explicada pelo contraste dos atributos (pessoais e referentes ao trabalho) entre brasileiros e imigrantes. Esse é o componente residual, que é denominado "componente discriminatório" ou "discriminação". Um valor negativo desse estimador representa maiores rendimentos para o grupo étnico/nacional em análise; se positivo, significa vantagem salarial para os brasileiros.

A análise do componente de discriminação deve ser feita com cautela, já que a precisão nas conclusões sobre o efeito de origem como fator de discriminação depende diretamente da especificação utilizada nas equações dos rendimentos. Em outras palavras, o componente discriminatório é aquele que não é explicado por nenhum dos determinantes utilizados no modelo. Dessa forma, quanto maior o número de variáveis relevantes para explicar os salários, menor o componente discriminatório. A não inclusão de variáveis importantes, devido à negligência ou à falta de dados, acarretará um peso maior do componente discriminatório (Gomes e Wajnman, 2005; Jann, 2008). Exemplo disso é a ausência de medida de background familiar. A sua omissão não anula os resultados das outras variáveis na equação, contudo pode reduzir o peso do componente discriminatório entre os grupos (Gomes e Wajnman, 2005), ou simplesmente mudar o valor do coeficiente de estimação da educação, já que essas variáveis são altamente correlacionadas.

A discriminação ocorre quando trabalhadores, cujos atributos produtivos são considerados idênticos, recebem salários diferentes. Essa diferença fundamenta-se em algumas características que não são consideradas produtivas e não são mensuradas no modelo ${ }^{20}$.

O componente explicado $E$, ou endowment, refere-se à diferença de remuneração resultante dos contrastes de características entre os grupos analisados, ponderado pelo valor dado às mesmas características para o grupo de referência. Ele demonstra como os dois grupos seriam remunerados, se não houvesse nenhum tipo de discriminação no mercado de trabalho (Gomes e Wajnman, 2005; Sala, 2005). Caso não haja diferença entre os grupos quanto aos atributos produtivos, tais como educação e experiência, o resultado do somatório será zero. Assim, o diferencial de rendimento está no componente não explicado, ou seja, no componente discriminatório, e não nas características e nas habilidades dos indivíduos. Na seção seguinte, apresento os resultados refe- 
Desigualdade e Discriminação de Imigrantes Internacionais no Mercado...

rentes às desigualdades de posição de classe e de rendimentos e ao componente discriminatório no mercado de trabalho brasileiro.

\section{OS RESULTADOS}

\section{Desigualdade de posição de classe e rendimentos}

A primeira análise refere-se às posições de classes dos grupos em estudo. Busco identificar se há diferença significativa na probabilidade de inserção de nativos e de imigrantes em posições de classes distintas. Os resultados podem ser vistos na Tabela 1 .

Tabela 1

Efeito da Variável “Origem” (Nacionalidade) sobre Posição de Classe no Mercado de Trabalho - Modelo Logístico Multinomial

\begin{tabular}{|c|c|c|c|c|c|c|c|c|}
\hline \multirow[t]{2}{*}{ Origem } & \multicolumn{2}{|c|}{$\begin{array}{c}\text { Modelo } 1 \\
\text { (BnM X Latinos) }\end{array}$} & \multicolumn{2}{|c|}{$\begin{array}{c}\text { Modelo } 2 \\
\text { (BnM_brancos X } \\
\text { asiáticos) }\end{array}$} & \multicolumn{2}{|c|}{$\begin{array}{c}\text { Modelo } 3 \\
\text { (BM X Latinos) }\end{array}$} & \multicolumn{2}{|c|}{$\begin{array}{c}\text { Modelo } 4 \\
\text { (BM_brancos X } \\
\text { asiáticos) }\end{array}$} \\
\hline & Classe 2 & Classe 3 & Classe 2 & Classe 3 & Classe 2 & Classe 3 & Classe 2 & Classe 3 \\
\hline Argentina & $-0,11$ & $-0,77^{* * *}$ & & & $-0,13$ & $-0,74 * * *$ & & \\
\hline Boliviana & $0,93^{* * *}$ & $-0,21$ & & & $0,88^{* * *}$ & $-0,20$ & & \\
\hline Chilena & $0,58^{* * *}$ & $-0,66^{* * *}$ & & & $0,54^{* * *}$ & $-0,66^{* * *}$ & & \\
\hline Paraguaia & 0,21 & $-0,13$ & & & $0,25^{* *}$ & 0,01 & & \\
\hline Peruana & $-0,17$ & $-0,98^{* * *}$ & & & $-0,27^{* *}$ & $-1,05^{* * *}$ & & \\
\hline Uruguaia & $0,17^{* *}$ & $-0,20$ & & & $0,18^{* *}$ & $-0,12$ & & \\
\hline Chinesa & & & $-1,71^{* * *}$ & $-2,71^{* * *}$ & & & $-1,64^{* * *}$ & $-2,62^{* * *}$ \\
\hline Coreana & & & $-1,16^{* * *}$ & $-2,26^{* * *}$ & & & $-1,19 * * *$ & $-2,29 * * *$ \\
\hline Pseudo $\mathrm{R}^{2}$ & \multicolumn{2}{|c|}{0,11} & \multicolumn{2}{|c|}{0,13} & \multicolumn{2}{|c|}{0,09} & \multicolumn{2}{|c|}{0,10} \\
\hline $\mathrm{N}$ & \multicolumn{2}{|c|}{3179818} & \multicolumn{2}{|c|}{1742952} & \multicolumn{2}{|c|}{880442} & \multicolumn{2}{|c|}{464130} \\
\hline
\end{tabular}

Fonte: IBGE, Censo Demográfico 2000 (subamostra). Dados trabalhados pela autora.

** significante ao nível de 5\%; *** significante ao nível de $1 \%$.

$\mathrm{BnM}=$ Brasileiros não migrantes; $\mathrm{BM}=$ Brasileiros migrantes .

Quando comparo a posição de classe entre brasileiros e bolivianos, chilenos, paraguaios e uruguaios, os brasileiros têm as maiores chances de estarem na classe 1, e não na classe 2 (ver Tabela 1). Os resultados são similares entre brasileiros e argentinos, bem como entre brasileiros e peruanos, já que, em geral, os estimadores não se apresentam estatisticamente significativos. As maiores probabilidades de estarem na classe 1, e não na classe 3 , são dos argentinos, dos chilenos e dos peruanos, e não dos brasileiros. Embora bolivianos, paraguaios e uruguaios 
tenham apresentado tendência de maior concentração na classe 1 , e não na classe 3, os resultados não são estatisticamente significativos, sugerindo maior similaridade do que diferença em relação aos brasileiros.

Em síntese, identifico que os latinos têm chances maiores ou similares de se inserirem em ocupações de maior prestígio, quando comparados aos brasileiros. Em outras palavras, eles tendem menos a localizarem-se em posições de classes de trabalhos semiqualificados ou não qualificados e rurais, em comparação aos nativos. Esse fato sugere a negação da hipótese de desvantagem desses grupos étnicos / nacionais no mercado de trabalho, quando comparados aos nativos.

No que se refere aos asiáticos, os resultados apresentam uma tendência mais acentuada de coreanos e de chineses pertencerem à classe 1, e não às outras classes, quando comparados aos brasileiros. Dito de outra forma, os nativos têm probabilidade bastante elevada de pertencerem à classe 3 e, em grau menor, à classe 2 (vide Tabela 1).

Os resultados quanto à posição de classe não suportam a ideia de que os grupos étnicos/nacionais estariam em pior situação ocupacional do que os nativos. Além disso, tais resultados corroboram as pesquisas internacionais recentes, quando apresentam uma heterogeneidade nas posições em que se encontram os imigrantes.

Os achados apresentam maiores discrepâncias no que diz respeito aos rendimentos, quando comparo latinos com brasileiros migrantes e com os não migrantes. É o que mostra a tabela que se segue.

Após controlar as características individuais e as referentes à situação de mercado, as origens argentina e chilena apresentam efeitos positivos sobre os rendimentos, isto é, os trabalhadores dessas nacionalidades / etnias tendem a ter salários melhores do que os brasileiros não migrantes, com valores de $24 \%$ e $8 \%$ superiores, respectivamente. Já os uruguaios tendem a receber rendimentos menores (5\% em média) do que os nativos não migrantes. Nos casos de bolivianos, paraguaios e peruanos, os coeficientes não são estatisticamente significativos, indicando assim que não existe diferença entre esses grupos e os brasileiros não migrantes, no que diz respeito aos ganhos salariais.

Nesse contexto, alguém pode questionar se as diferenças encontradas não se referem à variável origem, mas sim ao fato de ser migrante ou não migrante; ou seja, o efeito observado seria pelo fato de ser imigran- 
Desigualdade e Discriminação de Imigrantes Internacionais no Mercado...

Tabela 2

Efeito da Variável Origem (Nacionalidade) sobre Logaritmo de Rendimento Mensal, em Todos os Trabalhos - Modelo Heckman

\begin{tabular}{l|c|c|c|c}
\hline Origem & $\begin{array}{c}\text { Modelo 1 } \\
\text { (BnM X Lati- } \\
\text { nos) }\end{array}$ & $\begin{array}{c}\text { Modelo 2 } \\
\text { (BnM_brancos } \\
\text { X asiáticos) }\end{array}$ & $\begin{array}{c}\text { Modelo 3 } \\
\text { (BM X Latinos) }\end{array}$ & $\begin{array}{c}\text { Modelo 4 } \\
\text { (BM_brancos X } \\
\text { asiáticos) }\end{array}$ \\
\hline Argentina & $0,24^{* * *}$ & & $0,17^{* * *}$ & \\
\hline Boliviana & $-0,01$ & & $-0,14^{* * *}$ & \\
\hline Chilena & $0,09^{* * *}$ & & 0,01 & \\
\hline Paraguaia & 0,03 & & $-0,13^{* * *}$ & \\
\hline Peruana & 0,00 & & $-0,10^{* *}$ & \\
\hline Uruguaia & $-0,06^{* *}$ & & $-0,11^{* * *}$ & \\
\hline Chinesa & & $0,30^{* * *}$ & & $0,22^{* * *}$ \\
\hline Coreana & $0,49^{* * *}$ & $-0,23^{* * *}$ & 0,08 & $-0,40^{* * *}$ \\
\hline Lambda & 0,57 & $-0,28$ & 0,1 & $-0,47$ \\
\hline Rho & 3179818 & 1742952 & 880442 & 464130 \\
\hline N & & $0,51^{* * *}$ & &
\end{tabular}

Fonte: IBGE, Censo Demográfico 2000 (subamostra). Dados trabalhados pela autora.

** significante ao nível de 5\%. ${ }^{* *}$ significante ao nível de $1 \%$.

$\mathrm{BnM}$ - Brasileiros não migrantes; BM - Brasileiros migrantes.

te, independente das características referentes à nacionalidade. Afinal, a literatura pressupõe que imigrantes têm características próprias que os fazem mais capazes, trabalhadores, ambiciosos e produtivos permitindo-lhes que tenham sucesso econômico. A partir das alterações encontradas nos estimadores da variável "origem" entre imigrantes internacionais e brasileiros migrantes, sugiro que parte do efeito dos estimadores de origem, encontrados nos modelos 1 e 2, tem embutido o status de migrante afetando os rendimentos. Entretanto, caso o efeito fosse apenas o fato de "ser imigrante", excluindo o efeito de origem, os resultados dos estimadores dessa variável sobre os diferenciais de rendimentos entre imigrantes internacionais e brasileiros migrantes não seriam significativos e não teriam valores tão díspares, pois todos os grupos analisados nos modelos 3 e 4 dizem respeito aos migrantes (internacionais ou internos). Entretanto, os resultados foram mais significativos do que aqueles encontrados entre imigrantes internacionais e brasileiros não migrantes.

Quando os latinos são comparados aos nativos migrantes, o quadro altera-se. Bolivianos, paraguaios, peruanos e uruguaios apresentam coeficientes negativos, o que significa que eles estão associados a rendi- 
mentos menores em $14 \%, 15 \%, 9 \%$ e $11 \%$, respectivamente, do que os nativos; os chilenos deixam de ter coeficientes significativos, demonstrando assim possuírem rendimentos similares aos dos brasileiros migrantes; já os argentinos mantêm coeficientes positivos, mas com percentuais menores, no patamar de $17 \%$.

As variáveis referentes aos chineses e aos coreanos apresentam coeficientes positivos e significativos, quando comparadas aos brasileiros não migrantes e migrantes. Os chineses tendem a ter rendimentos superiores aos dois grupos de brasileiros em $34 \%$ e $23 \%$, respectivamente; os valores para os coreanos chegam a ser $66 \%$ e $53 \%$ superiores. Vale destacar que essas diferenças têm um peso ainda maior do que aparentam, uma vez que esses grupos étnicos/nacionais estão sendo comparados com os nativos brancos apenas, os quais são o grupo mais bem remunerado no país, como evidenciado por pesquisas empíricas (Soares, 2000; Campante, Crespo et alii, 2004).

Chamo atenção para o fato de que os coeficientes da variável origem dos imigrantes internacionais perdem intensidade quando controlo o status de migrante. No caso de argentinos, por exemplo, a diferença de rendimentos cai de $24 \%$ para $17 \%$ quando o grupo de comparação muda dos nativos não migrantes para migrantes. A alteração é maior para os coreanos, que mudam de $66 \%$ para $53 \%$. Quanto aos grupos étnicos/nacionais que apresentam rendimentos similares ou inferiores aos dos brasileiros não migrantes, há um aumento dessas diferenças ao serem comparados aos migrantes nacionais. Os bolivianos, os paraguaios e os peruanos passam a estar em desvantagem no mercado de trabalho, com salários menores em $14 \%, 13 \%$ e 9\%, respectivamente, vis-à-vis os brasileiros migrantes. Os uruguaios, que apresentam rendimentos inferiores aos brasileiros não migrantes, aumentam essa diferença negativa para $11 \%$. Esses dados reforçam a afirmativa de Santos Júnior e colaboradores (2005) de que os homens migrantes internos no Brasil são positivamente selecionados.

As análises dos diferenciais de rendimentos mostram também uma não homogeneidade quanto à situação dos imigrantes internacionais no Brasil, como ocorrido no exame das posições de classes. Esses resultados são similares aos encontrados nas pesquisas internacionais (Jong e Madamba, 2001; Van Tubergen, Maas e Flap, 2004; Kesler e Hout, 2010). Eles permitem supor que os imigrantes internacionais agregam-se em três grupos distintos. O primeiro é formado por coreanos e chineses, que apresentam salários e localizações ocupacionais melho- 
res do que os brasileiros, sejam migrantes, sejam não migrantes. O segundo grupo é formado por argentinos e chilenos, ainda em vantagem no mercado de trabalho quando comparados aos nativos, mas em um nível inferior aos dos asiáticos. Em terceiro lugar, vêm os bolivianos, os paraguaios, os peruanos e os uruguaios, que se encontram em patamar semelhante ou inferior na estrutura hierárquica do mercado de trabalho, em relação aos brasileiros. Em suma, os dados confirmam que há desigualdade étnico/nacional no mercado de trabalho brasileiro, uma vez que origem afeta as localizações ocupacionais e os rendimentos dos imigrantes internacionais.

Cabe lembrar que tais resultados estão próximos aos encontrados pelos estudos recentes no âmbito internacional. Eles não se adequam ao pressuposto dos pensadores da corrente do mercado dual que afirma que os imigrantes, em geral, se encontram nas ocupações da base da estrutura ocupacional, obtendo, consequentemente, rendimentos mais baixos do que os percebidos pelos nativos. As ideias de Sassen (1988) e de Portes e Bach (1985), bem como a de Light et alii $(1994 ; 1995)$ e de Bonacich (1973) são as mais indicadas para explicar a situação dos imigrantes internacionais no contexto brasileiro.

O que, porém, essa pesquisa traz de diferente das ideias correntes no senso comum? Os indivíduos, em geral, podem dizer que as diferenças entre os imigrantes e os brasileiros são esperadas, já que os primeiros têm maior ou menor nível de capital humano, são da raça/cor branca ou não branca, ou por conta de outros fatores referentes aos seus atributos produtivos. No entanto, esse estudo demonstra que, mantendo tais características constantes, além da posição no mercado de trabalho e das variáveis socialmente significativas - raça/cor, educação, experiência, horas de trabalho, números de postos de trabalho, posição de classe, estado civil e posição no domicílio -, as diferenças baseadas na origem ainda permanecem. Ele mostra também que as diferenças não são generalizantes dentro dos grupos de latinos e de asiáticos, conforme frequentemente se acredita. Isto é, entre esses grupos, há subgrupos em situação distinta no mercado de trabalho brasileiro. Tais achados levantam uma nova questão a ser analisada: quanto desses diferenciais deve-se à discriminação no mercado de trabalho?

\section{Análise da discriminação}

Segundo Borjas (1986), a discriminação salarial é reflexo também da discriminação no mercado de trabalho, quando os empregadores le- 
vam em consideração atributos como raça, gênero e origem nacional, no momento de realizarem a troca de salário por produto. Baseada nessa ideia, verifico se origem étnica/nacional é um componente discriminatório no mercado de trabalho. Para tanto, calculo modelos de decomposição de Oaxaca para o valor dos rendimentos salariais em todos os trabalhos de brasileiros e de imigrantes (Oaxaca, 1973; Silva, 1980).

Frequentemente, os estudos sobre a diferença de remuneração entre imigrantes e nativos utilizam uma variável binária, que separa a amostra em dois grupos (conforme foi feito anteriormente). Entretanto, tal procedimento não capta as possíveis distinções do impacto das variáveis explicativas para cada origem étnico/nacional. Por conseguinte, não mensura o peso de discriminação sobre os grupos de indivíduos. Sendo assim, proponho realizar a decomposição de rendimentos entre cada grupo étnico/nacional de imigrantes e de nativos no intuito de verificar o efeito de tais fatores.

A partir dos resultados das desigualdades expostos anteriormente, apresento algumas proposições para a análise de discriminação. A primeira é de que os resultados do componente discriminatório são diferentes entre os grupos de imigrantes: positivo em alguns casos e negativo em outros. A outra é de que a discriminação negativa é sofrida por bolivianos, paraguaios, peruanos e uruguaios e a positiva, por argentinos, chilenos, coreanos e chineses. A última é de que a discriminação negativa aumenta e a positiva reduz, quando o grupo de referência são os nativos migrantes.

De fato, a partir da Tabela 3, verifico que os resultados são desiguais quando se analisam as diferenças de rendimentos entre cada grupo de imigrantes internacionais e de brasileiros (migrantes ou não migrantes). Ou seja, há grupos que são discriminados positivamente e outros negativamente no mercado de trabalho. Vale lembrar que o sinal positivo significa vantagens salariais para os brasileiros; os negativos, desvantagens.

A Tabela 3 apresenta os diferenciais dos rendimentos médios dos grupos e os componentes explicado e não explicado, sendo esse último o elemento discriminatório. Quando analiso o primeiro termo dos diferenciais de rendas, isto é, as diferenças nos rendimentos médios dos grupos em análise (independente dos coeficientes dos estimadores das variáveis inseridas no modelo), verifico que os brasileiros têm proven- 
Desigualdade e Discriminação de Imigrantes Internacionais no Mercado...

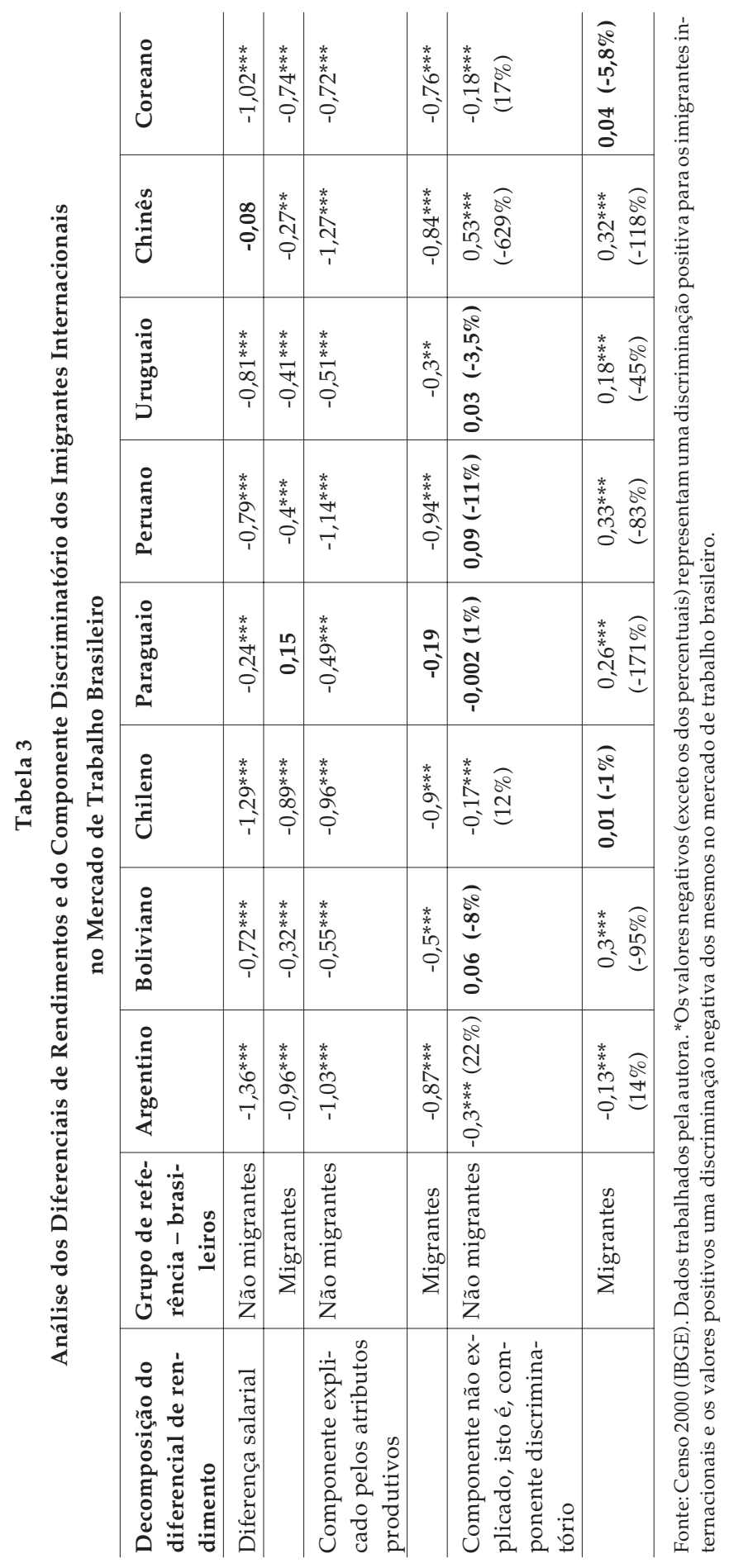


tos mais baixos do que os latinos e os asiáticos. Argentinos, chilenos e coreanos são os que apresentam as maiores médias salariais, em relação aos brasileiros. Já os paraguaios e os chineses detêm as menores médias, quando comparados aos brasileiros.

O termo explicado (endowments) demonstra que parte da vantagem salarial dos grupos étnicos / nacionais sobre os brasileiros deve-se ao fato de eles apresentarem atributos produtivos e localizações melhores no mercado de trabalho, como, por exemplo, maior nível educacional e experiência no mercado de trabalho, melhores posições de classes e maior concentração na área urbana. Ou seja, esse componente diz o quanto as variáveis do modelo de regressão explicam as diferenças encontradas nos salários dos grupos analisados. Chamo atenção para o fato de que todos os imigrantes, exceto paraguaios comparados aos brasileiros migrantes, apresentam, em média, melhores atributos produtivos que os nativos migrantes e não migrantes.

Vale destacar que esse resultado também mostra que capital humano é insuficiente para predizer o rendimento dos indivíduos. Os diferenciais de rendimentos não são explicados apenas por divergências quanto aos atributos produtivos dos indivíduos, mas pelo componente de discriminação ou o componente não explicado, que é o último termo representado na Tabela 3. Destaco, mais uma vez, que a ausência de variáveis importantes para explicar salários - provocada pela falta de dados - pode elevar o peso e o valor desse componente. Isto é, a inclusão de tais variáveis no modelo levaria à redução dos valores dos coeficientes estimados do componente não explicado, demonstrando uma maior precisão sobre o valor de uma discriminação pura. Contudo, esse fato não retira a importância dos achados, os quais demonstram que há outros fatores determinando os rendimentos dos homens no mercado de trabalho, além dos atributos produtivos, altamente valorizados (como, por exemplo, educação, raça, experiência, horas de trabalho, posição de classe, região, situação de moradia). Um desses fatores refere-se, provavelmente, à origem étnico/nacional do imigrante, sugerindo assim uma discriminação "pura".

Os dados mostram que, quando comparados aos brasileiros não migrantes, os argentinos, os chilenos e os coreanos encontram-se em vantagens na troca de capital por produto (visão do empregador) ou de produto por capital (visão do consumidor). Isso porque eles apresentam uma discriminação positiva no mercado de trabalho brasileiro. $\mathrm{Ou}$ 
seja, eles obtêm rendimentos melhores do que os nativos não migrantes, devido a outros fatores que não suas habilidades de produção. Em outras palavras, eles recebem, respectivamente, $22 \%, 12 \%$ e $17 \%$ a mais do que deveriam receber, considerando o capital humano, a localização no mercado de trabalho e a situação de residência. Tais diferenças podem aparecer pelo simples fato de serem originários de tais países, geralmente considerados mais desenvolvidos ou em estágio de desenvolvimento similar ao do Brasil. Outras explicações viriam do fato de pertencerem a um enclave étnico, de estar fora do mercado competitivo aberto, ou por causa de motivos não mensurados nos modelos.

No caso dos outros grupos de origem latina, o componente de discriminação não se apresenta estatisticamente significativo. Os chineses são os únicos que apresentam um coeficiente positivo, representando uma discriminação negativa para eles. Ou seja, eles deveriam ganhar $629 \%$ a mais do que ganham. Esse resultado é bastante interessante, uma vez que, nas análises anteriores das diferenças de posição de classe e de rendimentos, os chineses mostraram-se em melhor situação socioeconômica, quando comparados aos brasileiros. Entretanto, esse fato não ocorre com a análise da discriminação. Tal fato anula a pressuposição que supunha uma discriminação positiva para esse grupo. Uma possível explicação para esse achado pode se dar pelo fato de os chineses pertencerem a um enclave étnico. Nesse caso, fazer parte dele pode ter um impacto negativo para esses imigrantes. A possibilidade disso ocorrer existe, uma vez que nem sempre capital social ${ }^{21}$ acarreta vantagens para os seus membros (Portes, 2000; Lin, 2006). Segundo Portes (2000:146), estudos recentes verificaram que existem, no mínimo, quatro consequências negativas do capital social: exclusão dos não membros; exigências excessivas a membros do grupo; restrições à liberdade individual; e normas de nivelação descendente.

Outra justificativa talvez venha do fato de eles não terem o enclave como proteção e acabarem competindo no mercado de trabalho aberto, onde os empregadores ou consumidores preferem mais o convívio com pessoas de outros grupos com características diferentes das apresentadas pelos chineses, ocasionando a sua discriminação. Uma explicação distinta, mas não excludente, pode se dar pelo fato de que características não incluídas no modelo teriam efeito no sentido de reduzir o peso desse componente não explicado, como, por exemplo, tempo de residência no Brasil, idade ao migrar, o mismatch (uma sobre-educação na ocupação). Tais efeitos devem ser superiores para os chineses, já que 
eles têm percentuais mais altos de pessoas que imigraram com 41 anos de idade ou mais, com mismatch, e que residem há 10 anos ou menos no país (Vilela, 2008). Esse último fator parece relevante, dado que o salário inicial dos migrantes, por hora, é US $\$ 0,50$ menor do que o dos nativos (Jong e Madamba, 2001). No entanto, é importante dizer que essa diferença se reduz em $0,8 \%$ a cada ano de residência na sociedade hospedeira. Esse fato pode ser relevante para bolivianos, paraguaios e peruanos por terem, também, percentuais altos de pessoas com poucos anos de residência no Brasil.

Vale lembrar que os chineses e os coreanos estão sendo comparados com o grupo de brasileiros brancos, que costumam ganhar os melhores salários. Assim, os asiáticos apresentam diferenças salariais médias menores do que se esperaria, se eles fossem comparados com os brasileiros em geral, como é o caso dos latinos.

Quando comparados aos brasileiros migrantes, os argentinos são os únicos que continuam com um componente discriminatório positivo e estatisticamente significante. Eles ganham, em média, $14 \%$ a mais do que deveriam ganhar, controlando suas habilidades e suas localizações no mercado. Os outros grupos que apresentam coeficientes estatisticamente significativos recebem menos do que lhes cabem, a saber: bolivianos $(-95 \%)$, paraguaios $(-171 \%)$, peruanos (-83\%), uruguaios $(-45 \%)$ e chineses $(-118 \%)$. Tais resultados refutam a segunda pressuposição e confirmam a terceira.

Como pode ser verificado na Tabela 3, não só o sentido (positivo ou negativo) da discriminação é diferente para os grupos de imigrantes, mas também a sua intensidade. Os valores percentuais apresentados na tabela indicam a magnitude do componente não explicado sobre a remuneração, em benefício ou em prejuízo dos grupos étnicos/nacionais. Em outras palavras, a decomposição do diferencial de renda dos brasileiros e dos imigrantes demonstra o quanto de diferença salarial é referente aos atributos e às características dos indivíduos e o quanto é determinado por outros fatores, incluindo a discriminação.

Esses resultados são diferentes daqueles apresentados por Sala (2005) em seu estudo sobre a discriminação dos imigrantes oriundos do Cone Sul (argentinos, bolivianos, chilenos, paraguaios e uruguaios). Segundo a autora, apenas os bolivianos são discriminados negativamente no mercado de trabalho brasileiro. Talvez a diferença entre os achados possa ser explicada pela distinção entre as amostras, já que Sala (2005) 
analisou discriminação apenas dos imigrantes qualificados, ao passo que o presente estudo inclui tanto imigrantes qualificados quanto os não qualificados ${ }^{22}$.

Por outro lado, os resultados encontrados confirmam as ideias de Borjas (1986), Ferrer, Geen e Riddel (2004) e de Vainer (1995). Para eles, as diferenças de rendimentos no mercado de trabalho explicam-se pelas desigualdades na escolaridade, na experiência e também em função da discriminação exercidas por alguns empregadores. Isto é, esses podem pagar menos aos trabalhadores imigrantes do que aos naturais do país, devido a uma discriminação pura.

\section{CONSIDERAÇÕES FINAIS}

Quando analiso as diferenças nas posições de classe e nos rendimentos entre os grupos étnicos / nacionais e os brasileiros, verifico que, em geral, os imigrantes internacionais tendem a ser beneficiados ou estarem em condições iguais às dos nativos. Os benefícios são maiores para os argentinos, os chineses e os coreanos, seguidos, em menor grau, por chilenos. Isso acontece tanto no que diz respeito aos rendimentos quanto às posições de classe. Já bolivianos, paraguaios, peruanos e uruguaios tendem a estar em localizações ocupacionais similares ou melhores do que os brasileiros. No entanto, não apresentam vantagem em termos de ganhos salariais.

Quando o grupo de referência é o de brasileiros migrantes, os grupos de latinos e asiáticos tendem a manter suas vantagens quanto às posições de classes. Porém, os resultados alteram-se no que diz respeito aos rendimentos. Argentinos, coreanos e chineses continuam apresentando vantagens salariais, mas em menor grau. Os chilenos perdem suas vantagens, isto é, as diferenças passam a não ser estatisticamente significativas. Para bolivianos, paraguaios e peruanos a situação piora, ou seja, eles passam a demonstrar um impacto negativo da variável "origem" sobre seus rendimentos. No caso dos uruguaios, que já tinham apresentado um coeficiente negativo, quando comparados aos nativos não migrantes, apresentam um maior coeficiente negativo, passando de $5 \%$ para $11 \%$ a menos nos seus rendimentos.

Os resultados quanto à posição de classe não suportam a ideia de que os grupos étnicos/nacionais estariam em pior situação na hierarquia ocupacional no mercado de trabalho do que os nativos. Os achados são de que os imigrantes internacionais têm menores chances de se con- 
centrarem na classe 3 do que os brasileiros. Além disso, tais resultados corroboram as pesquisas internacionais recentes, quando apresentam uma heterogeneidade nas posições em que se encontram os imigrantes.

Outro ponto a considerar, demonstrado por essa primeira análise, é de que o status de migrante tem impacto positivo no mercado de trabalho. Isso é evidenciado pelas alterações apresentadas nos coeficientes da variável "origem/etnia". Isto é, quando controlo o status de ser migrante, as vantagens identificadas dos grupos étnicos / nacionais sobre os nativos não migrantes perdem peso ou deixam de existir. Esse fato confirma a visão de migração como capital humano.

A partir disso, apresento três pressuposições para a análise de discriminação. A primeira é de que ela apresenta resultados diferentes entre os grupos de imigrantes: positiva em alguns casos e negativa em outros. A segunda é de que a discriminação negativa é sofrida por bolivianos, paraguaios, peruanos e uruguaios e a positiva por argentinos, chilenos, coreanos e chineses. A terceira é de que a discriminação negativa aumenta e a positiva reduz, quando o grupo de referência são os nativos migrantes. A primeira e a última são confirmadas. A segunda é rejeitada, uma vez que, entre os chilenos e os coreanos, não verifico a discriminação positiva frente os brasileiros migrantes; além disso, os chineses apresentam uma possível discriminação negativa, quando comparados aos brasileiros em geral.

Como pode ser visto, não são todos os imigrantes que são discriminados negativamente no mercado de trabalho. Uma possível explicação encontra-se na existência de um enclave étnico estabelecido por alguns grupos de imigrantes, o que pode ser o caso dos coreanos no Brasil com suas firmas étnicas. As confecções, no bairro Bom Retiro na cidade de São Paulo, são um bom exemplo disso. Entretanto, em alguns casos, pertencer a um enclave étnico pode ser desvantajoso para os seus membros. É o que parece acontecer com os chineses no país. O teste de tal hipótese é um ótimo tema para estudo futuro.

Outra sugestão de explicação baseia-se na afirmativa de Vainer (1995) de que a discriminação estigmatizante é maior quando o país de origem está em uma posição inferior (do ponto de vista econômico, político e simbólico) vis-à-vis o país receptor. Segundo o autor, o processo migratório produz relações assimétricas entre estados nacionais. Essas relações manifestam-se no quotidiano dos imigrantes, a partir da dis- 
criminação, da exploração e da dominação dos nativos sobre eles. De fato, os dados sugerem uma situação vantajosa para os imigrantes que são oriundos de países tidos como emergentes, mais desenvolvidos ou em estágio de desenvolvimento semelhante ao do Brasil, como é o caso da Argentina, do Chile e da Coreia. O oposto é encontrado para os originários da Bolívia, do Paraguai, do Peru, do Uruguai e da China, que apresentam um componente discriminatório negativo. Não é demais lembrar que falo da China dos anos anteriores à data do Censo (2000), que estava longe de ser a potência econômica que é hoje.

É importante ressaltar que, com os resultados da Decomposição de Oaxaca, mais uma vez, o status de migrante apresenta-se como um fator que impacta positivamente os rendimentos dos brasileiros. Essa é mais uma confirmação de que a imigração pode e deve ser considerada como capital humano, como foi proposto por Schulzts (1973). Dessa forma, torna-se uma variável indispensável na análise da situação dos indivíduos no mercado de trabalho.

Partindo desses achados, surge uma questão para reflexão futura: será que os grupos de imigrantes que apresentam um componente discriminatório desfavorável no mercado de trabalho brasileiro, comparados aos brasileiros não brancos apenas - os quais se encontram em desvantagens econômicas e sociais no sistema de estratificação brasileiro (Silva, 1981; Hasenbalg e Silva, 2003) -, estão em pior situação no mercado de trabalho? Essa é uma análise importante para o desenvolvimento dos estudos de estratificação social e desigualdade no Brasil.

(Recebido para publicação em agosto de 2010)

(Reapresentado em março de 2011)

(Aprovado para publicação em maio de 2011) 


\section{NOTAS}

1. Capital incorporado pelos seres humanos, especialmente nas formas de educação, saúde, experiência no mercado de trabalho, saúde e migração.

2. Podem ser consumidores também, no caso dos trabalhadores por conta-própria.

3. Segundo Piore e Sabel (1984), os fatores que geram o mercado dual são, principalmente, os seguintes: a) os requerimentos impostos sobre a força de trabalho; b) uma simples e pura discriminação no mercado de trabalho; c) fortes resistências para mudar e agir em prol de esforços contra a pobreza, isto porque existem pessoas, ou grupo de pessoas, interessadas em perpetuar a pobreza; d) acomodação do trabalhador ao tipo de emprego; e) finalmente, entre os pobres, as outras fontes de renda, especialmente a assistência pública e a atividade ilícita, tendem a ser mais compatíveis com o setor secundário do que com o primário.

4. A dualidade desse mercado segmentado não está nas características observáveis dos postos de trabalho, tais como ramo de atividade ou formalidade, mas sim na questão dos retornos encontrados nos setores que podem coexister em um mesmo negócio.

5. Defino aqui enclave étnico como uma concentração de firmas étnicas, isto é, aquelas de diversos tamanhos gerenciadas e de propriedade de membros de uma minoria nacional ou cultural identificável, as quais empregam um número significativo de trabalhadores pertencentes ao mesmo grupo minoritário (Portes e Jensen, 1989).

6. O caso dos bolivianos é o mais expressivo (Silva, 1998; 2002; 2006; Bassegio, 2004; Sala, 2005).

7. A definição de imigrante usada neste estudo (tanto para interno quanto para internacional) é aquela de Sayad (1998:54 e 55), isto é, "um imigrante é essencialmente uma força de trabalho, e uma força de trabalho provisória, temporária, em trânsito. Em virtude desse princípio, um trabalhador imigrante (sendo que trabalhador e imigrante são, neste caso, quase pleonasmo), mesmo se nasce para a vida (e para a imigração) na imigração, mesmo se é chamada a trabalhar (como imigrante) durante toda a sua vida no país, mesmo se está destinado a morrer (na migração), como imigrante, continua sendo um trabalhador definido e tratado como provisório, ou seja, revogável a qualquer momento." Nesse caso, não importa o tempo de residência do indivíduo no território de destino, o imigrante será sempre um imigrante.

8. Chineses: contêm os números de chineses e taiwaneses juntos, uma vez que Taiwan não é considerado independente, politicamente falando, da China, por diversos governantes de outros países, no momento de coleta dos dados do Censo.

9. Coreanos: incluem os imigrantes originários da Coreia do Sul e da Coreia do Norte.

10. Destaco que, daqui para frente, usarei apenas a designação "brasileiros migrantes", descartando o termo interno.

11. A escolha dos imigrantes interestaduais, no lugar dos intermunicipais, partiu da ideia de que pode haver uma maior semelhança entre imigrantes internacionais e imigrantes internos interestaduais, quanto às características pessoais ou grupais dos imigrantes, uma vez que a migração para outro estado da Federação apresenta maiores dificuldades, custos e riscos (assim como a imigração internacional) do que uma migração para outro município, em um mesmo estado. 
12. Chamo atenção para o fato de que tal abordagem está focada na análise de imigrantes trabalhadores e não de imigrantes refugiados, ou que buscam reunificação familiar. Chiswick (1999) afirma que a seletividade favorável para imigrantes é menos intensa entre os imigrantes que se guiam por motivos diferentes do sucesso econômico, tais como: acompanhamento de familiares; fuga de perseguições políticas ou religiosas; caráter ideológico, entre outros.

13. Ressalto aqui que há grandes diferenças entre a inserção no mercado de trabalho entre homens e mulheres, mas, uma vez que não é este o foco de estudo deste projeto, delimitei a análise apenas de homens no mercado de trabalho.

14. Esta ideia não descarta aqueles que estudam e trabalham ao mesmo tempo, mas tenta evitar que classifiquemos como desocupados os indivíduos que estejam estudando e não trabalhando.

15. Essas variáveis não tratam do cerne da minha discussão. Por isso, não são apresentadas no texto; apenas no Apêndice I.

16. Para constituição de tal variável, utilizo a ocupação antiga do Censo de 1991 compatibilizada para a variável referente às ocupações do Censo de 2000. Considero a sintaxe do índice de EGP (Erickson, Goldthorpe et alii, 1979), cedida pelo Instituto do Milênio (Grupo de pesquisa interinstitucional sobre estratificação social).

17. Essa classe entra no modelo devido apenas pelo fato de eu ter incluído pessoas que não trabalhavam, na semana de referência, na análise, para controlar o viés de seleção nas amostras de rendimento e posição ocupacional. Por isso, ela não será analisada ao longo do texto, embora o modelo a inclua.

18. As diferenças entre as categorias não são homogêneas e, assim, a hierarquia não é tão precisa. Por isso, uso a logística multinomial para análise e não a logística ordinal. Para maiores detalhes sobre a logística ordinal conferir Agresti (1996).

19. Para melhor compreensão da logística multinomial, verificar Agresti (1996).

20. Jacinto (2005) diz que há três categorias de discriminação no mercado de trabalho: 1) o poder de monopólio dá origem à discriminação; b) o preconceito estatístico, onde o empregador projeta no indivíduo algumas características observadas no grupo ao qual o candidato pertence; 3 ) o preconceito pessoal, pelo qual os empregadores, empregados ou consumidores preferem o convívio com pessoas pertencentes a grupos de características específicas, como, por exemplo, de sexo ou de raça, e assim excluem os outros.

21. Assumo aqui o enclave étnico como uma forma de capital social

22. Chamo atenção aqui para o fato de um possível erro nos resultados de Sala (2005), uma vez que ela, no segundo termo da decomposição, acrescenta os valores das médias dos brasileiros e não dos imigrantes, como seria adequado (cf. Oaxaca, 1973; Silva, 1981; Gomes e Wajnman 2005; Jong e Madamba, 2001). Entretanto, vale considerar que o erro pode ter sido apenas de digitação do texto e não nos cálculos da Decomposição de Oaxaca. 


\section{REFERÊNCIAS BIBLIOGRÁFICAS}

AGRESTI, Alan (1996), An introduction to categorical data analysis. New York, John Wiley \& Sons. (Wiley series in probability and statistics).

ÂNTICO, Cláudia (1998), Imigração internacional no Brasil durante a década de 80: explorando alguns dados do Censo de 1991. XI Encontro Nacional de Estudos Populacionais da ABEP. Caxambu, ABEP. Disponível em http://www.abep. nepo. unicamp.br/docs/anais/PDF/1998/a147.pdf

AYDEMIR Abdurrahman B. (2003), Are Immigrants Positively or Negatively Selected? The Role of Immigrant Selection Criteria and Self-Selection. Disponível em http: / / ideas.repec.org/p/wpa/wuwpla/0306002.html

BORJAS, George. (1986), Labor economics. New York, McGraw-Hill.

BASSEGIO, Luiz (2004), Migrantes: discriminados e necessários? Disponível em http:/ / www.social.org.br/relatorio2004/relatorio021.htm

BONACICH, Edna. (1973), "A theory of middleman minorities". American Sociological Review [S.I.], v. 38, n. 5, pp. 583-594. Disponível em http://www.neiu.edu/ circill/benjamin/psci411b/theory.pdf

CAMPANTE, Felipe. R. et alii (2004), "Desigualdade salarial entre raças no mercado de trabalho urbano brasileiro: aspectos regionais". RBE [S.I.], v. 58, n. 2, pp. 185-210.

CHISWICK, Barry R. (1999), "Are immigrantes favorably self-selected?” The American Economic Review [S.I.], v. 89, n. 2, pp. 181-185.

DICKENS, W. T.; LANG, K. (1985), "A test of dual labor market theory". American Economic Review [S.I.], v. 75, n. 4, pp. 792-805.

ERICKSON, R. et alii (1979), “Intergenerational mobility in three Western European industrial societies". British Journal of Sociology [S.I.], v. 30, pp. 415-441. Disponível em http:/ /ftp.iza.org/dp131.pdf

FERRER, Ana; GREEN, David A. e RIDDEL, W. Craig. (2004), International adult literacy survey: the effect of literacy on immigrant earnings. Ottawa, Statistics Canada (Minister of industry) catalogue n. 89-552-XPE, n. 12.

FRIEDBERG, Rachel M. (2000), "You can't take it with you? Imigrant Assimilation and the portability of human capital". Journal of Labor Economics [S.I.], v. 18, n. 2, pp. 221-251. Disponível em http://www.econ.brown.edu/fac/RachelãFriedberg/Links/friedbergãjole.pdf

GOLGHER, André B. (2006), “Diagnóstico do processo migratório no Brasil 1: comparação entre não-migrantes e migrantes". Texto para discussão n. 282. Cedeplar, 45pp. Disponível em http://www.cedeplar.ufmg.br/pesquisas/td/TD\%20282.pdf

GOMES, Anderson; WAJNMAN, Simone (2005), “Diferenciais salariais segundo a posição de homens e mulheres nas famílias". Seminário: as famílias e as políticas públicas no Brasil. Belo Horizonte. Disponível em http://www.abep.nepo.unicamp.br/ docs/anais/outros/FamPolPublicas/GomesWajnman.pdf

GUIMARÃES, Nádia A. (2009), Desemprego, uma construção social: São Paulo, Paris e Tóquio. Belo Horizonte, Argvmentvm. 
HALTER, Marylin. (2007), “Cultura econômica do empreendimento étnico: caminhos da imigração ao empreendedorismo". RAE [S.I.], v. 47, n. 1, pp. 116-123. Disponível em http://rae.fgv.br/sites/rae.fgv.br/files/artigos/10.1590_S0034- 7590200 7000100010.pdf

HASENBALG, Carlos; SILVA, Nelson do Valle. (2003), Origens e destinos - desigualdades sociais ao longo da vida. Rio de Janeiro, Topbooks.

HECKMAN, James. (1979), "Sample selection bias as a specification error". Econometrica, vol 47 (1), pp. 153-162.

HOLLINGSHEAD, A. B. (1975), Four Factor index of social status. Unpublished working paper. New Haven, Departament of Sociology Yale University. Disponível em http:/ / yale.edu/sociology/faculty/docs/hollingsheadãsocStat4factor.pdf

IBGE. Censo Demográfico Brasileiro - 2000. Rio de Janeiro, 2000. CD-Rom.

JACINTO, Paulo de A. (2005), "Diferenciais de salário por gênero na indústria avícola da Região Sul do Brasil: uma análise com microdados". RER [S.I.], v. 43, n. 3, pp. 529-555. Disponível em http:/ / www.scielo.br/pdf/resr/v43n3/27745.pdf

JANN, Ben (2008), “A stata implementation of the Blinder-Oaxaca decomposition”. ETH Zurich Sociology Working Papers. pp. 1-24, Zurich, ETH Zurich. Disponível em http://repec.ethz.ch/ets/papers/jann_oaxaca.pdf

JONG, Gordon F. D.; MADAMBA, Anna B. (2001), “A double disadvantage? Minority group, immigrant status, and underemployment in the United States". Social Science Quarterly [S.I.], v. 82, n. 1, pp. 117-129. Disponível em http://onlinelibrary.wiley. $\mathrm{com} / \mathrm{doi} / 10.1111 / 0038-4941.00011 / \mathrm{pdf}$

KESLER, Christel.; HOUT, Michael. (2010), “Entrepreneurship and immigrant wages in US labor markets: A multi-level approach". Social Science Research [S.I.], v. 39, n. 2, pp. 187-201.

LIGHT, Ivan et alii (1995), "Ethnic economy or ethnic enclave economy?" New migrants in the marketplace: Boston's ethnic entrepreneurs [S.I.], pp. 23.

(1994), "Beyond the ethnic enclave economy". Soc. Probs. [S.I.], v. 41, pp. 65.

LIN, Nan (2006), Social capital: a theory of social struture and action. Cambridge, Cambridge University Press.

MARTES, Ana Cristina B. (2009), “Velho tema, novos desafios - gestão pública da imigração". Cadernos Adenauer [S.I.], v. X, n. 1, pp. 9-27.

MASSEY, Douglas S. et alii (1993), "Theories of international migration: a review and appraisal". Population and Development Review [S.I.], v. 19, n. 3, pp. 431-466.

MINCER, Jacob A. (1974), Schooling, Experience, and Earnings (Human Behavior and Social Institutions n. 2). New York, Natonal Bureau of Economic Research.

OAXACA, Ronald L. (1973), “Male-Female wage differentials in urban labor markets". International Economic Review [S.I.], v. 14, pp. 693-709.

PIORE, Michael J. (1979), Birds of passage: Migrant labor and industrial societies. Cambridge, University Press Cambridge.

PIORE, Michael J.; SABEL, Charles (1984), The Second Industrial Divide: Possibilities For Prosperity. New York, Basic Books. 


\section{Elaine Meire Vilela}

PIORE, Michael J.; SAFFORD, Sean (2007), "Preliminary thoughts on identity and segmentation". Socio-Économie du travail, Économies et Societes AB [S.I.], v. 28, pp. 925-939.

PORTES, Alejandro (2000), “Capital social: origens e aplicações na Sociologia contemporânea". Sociologia, problemas e práticas [S.I.], n. 33, pp. 133-158.

(1995), The econimic Sociology of immigration: ensaios on networks, ethnicity, and entrepreneurshipp. New York, Russell Sage Foudation.

PORTES, Alejandro; BACH, Robert (1985), Latin journey: Cuban and Mexican immigrants in the United States. Univ of California, Pr on Demand.

PORTES, Alejandro; JENSEN, Leif (1989), “The enclave and the entrants: patterns of ethnic enterprise in Miami before and after Mariel". American Sociological Review [S.I.], v. 54, n. 6, pp. 929-949. Disponível em http://www.jstor.org/stable/2095716?seq=2

PORTES, Alejandro; RUMBAUT, Rubén G. (1990), Immigrant America: a portrait. Berkeley, University of California.

RIBEIRO, Carlos A. da C. (2003), “Estrutura de classes, condições de vida e oportunidades de mobilidade social no Brasil", in C. Hasenbalg e N. do V. Silva (eds.), Origens e destinos: desigualdades sociais ao longo da vida. Rio de Janeiro, Topbooks, pp. 381-425.

RIVERO, Patrícia S. (2009), Trabalho: opção ou necessidade? Um século de informalidade no Rio de Janeiro. Belo Horizonte, Argvmentvm.

SAKAMOTO, Arthur.; FURUICHI, Satomi (1997), "Wages among white and japanese-american male workes". Research in Stratification and Mobility [S.I.], v. 15, pp. 177-206.

SALA, Gabriela A. (2005), Características demográficas e sócio-ocupacionais dos migrantes nascidos nos países do Cone Sul residentes no Brasil. Tese de Doutorado. Departamento de Demografia, Universidade Federal de Minas Gerais, Belo Horizonte. 243p f. Disponível em http://www.cedeplar.ufmg.br/demografia/teses/2005/ Gabriela_AdrianaãSala.pdf

SANTOS JÚNIOR, Enertor da R. dos; Menezes-Filho, Naércio; Ferreira, Pedro C. (2005), "Migração, seleção e diferenças regionais de renda no Brasil". Pesquisa e Planejamento Econômico [S.I.], v. 35, n. 3, pp. 299-332. Disponível em http://www.ppe.ipea. gov.br/index.php/ppe/article/viewFile/47/25

SASSEN, Saskia. (1998), As cidades na economia mundial. São Paulo, Studio Nobel.

(1990), The Mobility of Labor and Capital: A Study in International Investment and Labor Flow. Cambridge, Cambridge University Press.

SAYAD, Abdelmalek (1998), A imigração: ou os paradoxos da alteridade. São Paulo, Universidade de São Paulo.

SCHULTZ, Theodore W. (1973), O capital humano: investimentos em educação e pesquisa. Rio de Janeiro, Ed. Zahar.

SENNA, José Júlio. (1976), “Escolaridade, experiência no trabalho e salários no Brasil”. Revista Brasileira de Economia, vol. 30, n. 2, abr./jun.

SILVA, Nelson do Valle. (2003), “Os rendimentos pessoais", in C. Hasenbalg e N. do V. Silva (eds.), Origens e destinos: desigualdades sociais ao longo da vida. Rio de Janeiro, Topbooks, pp. 431-456. 
Desigualdade e Discriminação de Imigrantes Internacionais no Mercado...

. (1981), “Cor e o processo de realização sócio-econômica". DADOS, vol. 24, no 3, pp. 391-409.

. (1980), “O preço da cor: diferenciais raciais na distribuição da renda no Brasil - réplica”. Pesquisa e Planejamento Econômico [S.I.], v. 10, n. 3, pp. 1007-1011.

. (1988), Uma classificação ocupacional para o estudo da mobilidade e da situação de trabalho no Brasil. Manuscrito.

SILVA, Sidney A. da (2006), "Bolivianos em São Paulo: entre o sonho e a realidade". Estudos Avançados [S.I.], v. 20, n. 57, pp. 157-170.

. (2002), Festejando a virgem mãe/terra numa pátria estrangeira: devoções marianas num contexto de permanências e mudanças culturais entre os imigrantes bolivianos em São Paulo. Tese de Doutorado - Departamento de Antropologia, Universidade de São Paulo, São Paulo. 326p f.

. (1998), "Costureiros hoje oficinistas amanhã? Indagações sobre a questão da mobilidade econômica e social entre os imigrantes bolivianos em São Paulo". Encontro Nacional sobre Migração, 1. Curitiba, novembro 1997. Anais... Curitiba [S.I.], pp. 383-394.

SOARES, Sergey. S. D. (2000), O perfil da discriminação no mercado de trabalho - homens negros, mulheres brancas e mulheres negras. IPEA - Texto para discussão 769 [S.I.].

VAN TUBERGEN, Frank (2005), "Self-employment of immigrants: A cross-national study of 17 western societies". Social Forces [S.I.], v. 84, n. 2, pp. 709-732, Dec.

, MAAS, Ineke e FLAP, Henk. (2004), “The economic incorporation of immigrants in 18 western societies: origin, destination, and community effects". American Sociological Review [S.I.], v. 69, n. 5, pp. 704-727.

VILELA, Elaine M. (2008), Imigração internacional e estratificação no mercado de trabalho brasileiro. Tese de Doutorado - Departamento de Sociologia e Política, Universidade Federal de Minas Gerais, Belo Horizonte. 166p f.

. (2002), Sírios e libaneses e o fenômeno étnico: os jogos de identidades. Dissertação de Mestrado - Departamento de Sociologia e Antropologia, Universidade Federal de Minas Gerais, Belo Horizonte.

ZAVODNY, Madeline. (2003), "Determinants of immigrant selectivity and skills". Research in Labor Economics [S.I.], vol. 22, pp. 269-289.

ZENG, Zhen e XIE, Yu. (2004), “Asian Americans's Earnings Disadvantage Reexamined: The Role of Place of Education". AJS [S.I.], vol. 109, pp. 1075-1108. 


\section{Apêndice I}

\section{Variáveis de controle}

2 -Educ (anos de estudos): essa é uma variável discreta ordinal que vai de 0 a 17 anos de estudo ou mais. Ela é considerada a principal variável de capital humano e pressupõe que, quanto maior o nível educacional, maiores são as chances de inserção em posições mais valorizadas na estrutura ocupacional do mercado de trabalho e maiores são os salários* dos indivíduos.

\section{3 - Exp (Experiência) é calculada subtraindo-se, da idade, o número de} anos de estudos, acrescido de seis (6) anos, que correspondem ao tempo necessário para o indivíduo inserir-se no sistema de ensino formal ${ }^{* *}$. Essa variável é discreta ordinal e fundamenta-se na ideia de Mincer (1974), entre outros teóricos, de que, quanto maior a experiência no mercado de trabalho, maiores são as vantagens salariais e de inserção em melhores ocupações. Segundo o autor, experiência representa o investimento após o período escolar formal, o qual engloba treinamento formal e treinamento informal, além do learning by doing. Por isso, essa também é uma medida de capital humano controlada nos modelos. Além dessa deve-se acrescentar a variável experiência de trabalho ao quadrado (Exp2) (Mincer, 1974). Isto porque as funções de salário e de status ocupacional são parabólicas (ou convexas), uma vez que anos

* Vale ressaltar que a literatura (Sena, 1976; Ferrer, Green e Riddell, 2004) destaca que pode ocorrer viés no coeficiente da variável "anos de escolaridade" por, basicamente, omissão de diferentes habilidades individuais e de diferenças na qualidade de ensino recebido. Isto é, o fato de haver correlação positiva entre escolaridade e habilidade individual e qualidade educacional, caso não se inclua na função salário e status ocupacional uma variável que represente habilidades e qualidade de ensino, será produzido um viés para cima no coeficiente da variável "anos de estudo". Melhor dizendo, "anos de estudo" estaria captando, também, parte do efeito das variáveis omitidas. Há também a omissão, inevitável, de variáveis importantes de status ocupacional e educacional dos pais. Essas variáveis são essencialmente importantes para o caso do Brasil, pela forte transmissão intergeracional de capital cultural, como destacado por Campante, Crespo e Leite (2004). Essas variáveis de capital cultural produzem efeitos indiretos em educação do indivíduo. Essas omissões devem-se ao fato de que estas informações não se encontram disponíveis na base de dados utilizada (Censo de 2000). Apesar disso, os resultados a serem encontrados nesse trabalho são de grande relevância. Como mostrou, muito bem, Silva (1980), a omissão destas variáveis não anula os resultados das outras. A inclusão destas variáveis só aumentaria os valores estimados.

** Essa variável apresenta alguns problemas. Ela considera que: a) todos os indivíduos ingressaram na escola aos seis anos de idade; $b$ ) que todos eles finalizaram a educação formal no tempo correto (isto é, o indivíduo não repetiu nenhuma série durante sua vida educacional); c) os indivíduos não trabalhavam enquanto estudavam (ou seja, não adquiriram experiência no mercado de trabalho); e d) os indivíduos sem escolaridade começaram a trabalhar aos seis anos de idade. Embora não muito boa essa medida de experiência no mercado de trabalho, ela é melhor do que simplesmente a idade do indivíduo, que considera que o mesmo começou a trabalhar ao nascer (cf. Gomes e Wajnman, 2005). 
adicionais de experiência no trabalho, após um limite, estão sujeitos a retornos decrescentes. Isto é, no início da carreira do trabalhador, o acréscimo no rendimento é rápido, mas tende a se reduzir após alguns $\operatorname{anos}^{* * *}$.

4 - TerRelig (Religião) é uma variável binária, em que zero (0) representa aqueles indivíduos que não têm religião e um (1) refere-se àqueles que têm. Está sendo usada aqui como proxy de capitais cultural e social, conforme sugere Vilela (2002). A autora verificou que a igreja (espaço de frequência religiosa) é um local de encontros, de manutenção da cultura de origem e da língua natal, além de ser o espaço de estreitamento dos laços de amizade e de solidariedade mútua. Dessa forma, parto do pressuposto de que quem não tem religião está em desvantagem por não ter acesso às redes sociais e aos sistemas de manutenção da cultura de origem inseridos nos grupos religiosos.

5 - Branca (cor/raça): variável binária, que representa cor/raça, codificada como zero ( 0 = não branca $)$ e um ( 1 = branca). Essa última categoria inclui as pessoas que se autoidentificam como brancas ou amarelas. As outras identificações (parda, negra, indígena e ignorada) fazem parte da categoria não branca. Trata-se de uma variável de alto significado social no Brasil, muito importante para explicar as diferenças salariais, de posição e de status ocupacional no país, conforme mostram diversos autores (Silva, 1980; 1981; Soares, 2000; Hasenbalg e Silva, 2003; Campante, Crespo et alii, 2004).

6 - Estado civil: informação codificada em quatro variáveis binárias: casado, separado (inclui os divorciados e os desquitados), viúvo e solteiro (categoria de referência). Esse é um fator importante no cálculo de status social e diferenciais de salários devido aos distintos caminhos que membros familiares adultos tomam na participação no sistema econômico, provenientes das relações dentro do grupo (Hollingshhead, 1975).

7 - Posidom (Posição na hierarquia do domicílio) é formada por quatro variáveis binárias: responsável (categoria de referência); cônjuge do responsável (cônjuge); filho ou enteado do responsável (filho), outras posições no domicílio (Outposdom). Essa última categoria é formada

\footnotetext{
*** Nesse contexto, o cálculo de retorno de experiência nos modelos de análise tem a seguinte fórmula: $\left(\beta x+2^{*} \beta y^{*} \text { Experiência fixa }\right)^{*} 100$, onde: $\beta x=$ coeficiente da variável experiência; $\beta y=$ coeficiente da variável experiência ao quadrado; Experiência fixa: 1, 2, 3.... ou mais anos.
} 
por todos os outros residentes no domicílio (avós, netos, bisnetos, empregado doméstico, entre outros). Essa variável, segundo Silva (2003), é relevante para a compreensão dos rendimentos e posições dos trabalhadores no mercado de trabalho.

8 - Região é dividida em cinco variáveis binárias, a saber: Norte; Nordeste; Centro-Oeste, Sul e Sudeste, sendo esta última a categoria de referência. Trata-se de uma variável importante nos estudos sobre mercado de trabalho no Brasil, haja vista a grande heterogeneidade regional no país (Soares, 2000; Hasenbalg e Silva, 2003; Campante, Crespo et alii, 2004; Sala, 2005).

9 - Urbano (Situação de residência): variável binária que se refere à localização de moradia dos indivíduos: urbano $(=1)$ ou rural $(=0)$. Tomando como referência as diferenças regionais, parte-se do pressuposto de que a situação da residência em área urbana afeta positivamente a inserção dos indivíduos no mercado de trabalho e, também, os seus rendimentos (Hasenbalg e Silva, 2003).

10 - Posição de classe já definida anteriormente. Trata-se de variável importante para definir os alcances econômicos dos indivíduos e deve ser controlada em uma equação de rendimentos.

11- Hora refere-se ao total de horas trabalhadas, por mês, em todas as ocupações. Estudos anteriores demonstraram que tal variável deve ser controlada, principalmente no caso dos imigrantes, pois esses tendem a trabalhar por muito mais horas do que os nativos (Sakamoto e Furuichi, 1997). O seu impacto sobre o rendimento total dos indivíduos é de uma relação causal, o que não acontece em relação à posição na hierarquia ocupacional. Nesse caso, ela é consequência e, por isso, não entra no Modelo Logístico Multinomial.

12- QuantTrab (Quantidade de Trabalho) significa a quantidade de trabalho que o indivíduo tinha na semana de 23 a 29 de julho de 2000 (semana de referência do Censo de 2000), que pode ser zero (0), um (1), dois ou mais (2) trabalhos. A hipótese é de que trabalhadores com dois ou mais serviços podem completar melhor a renda no mês. Essa variável, também, só entra no Modelo Heckman e não na regressão logística, devido ao motivo exposto anteriormente. 
Desigualdade e Discriminação de Imigrantes Internacionais no Mercado...

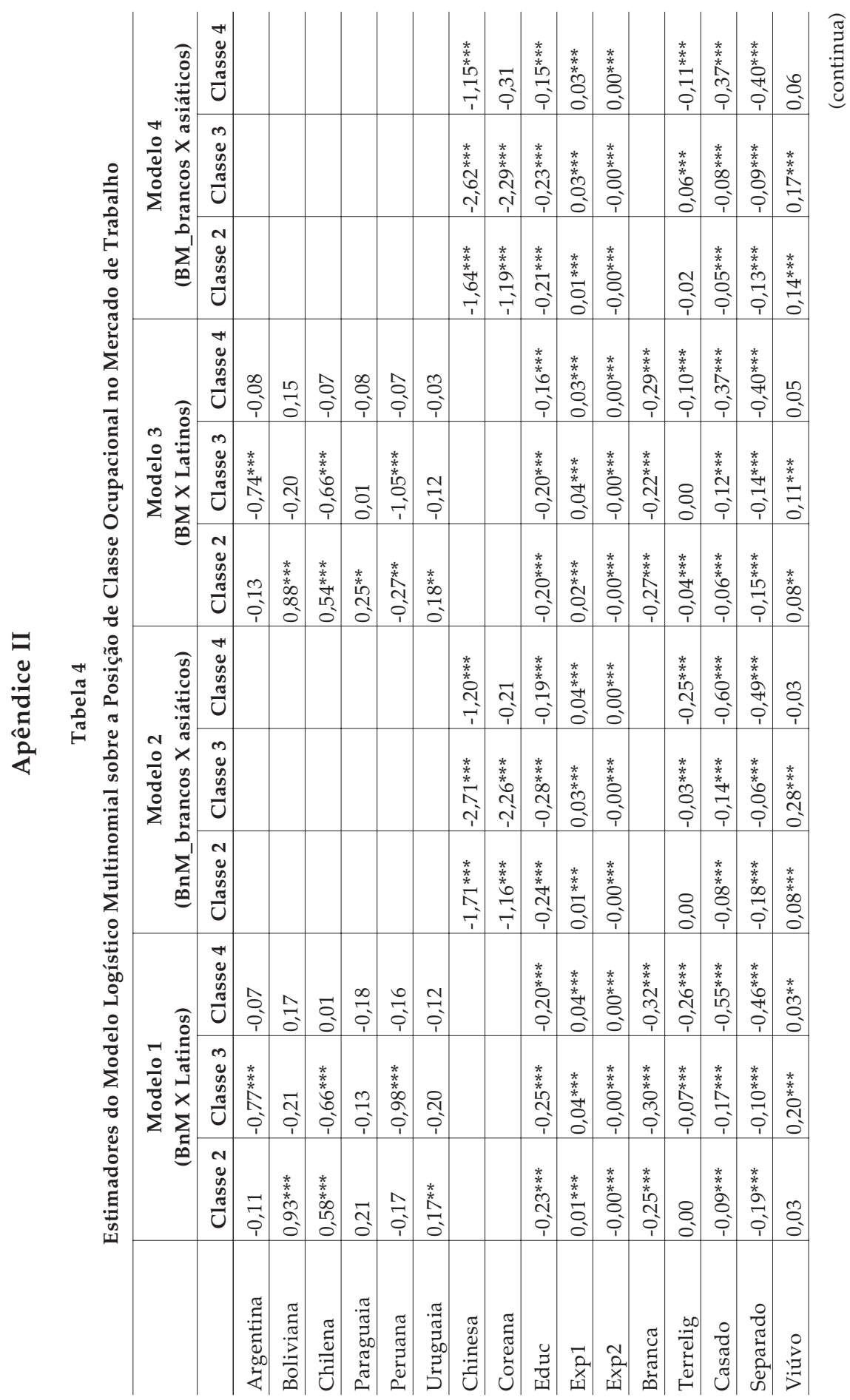




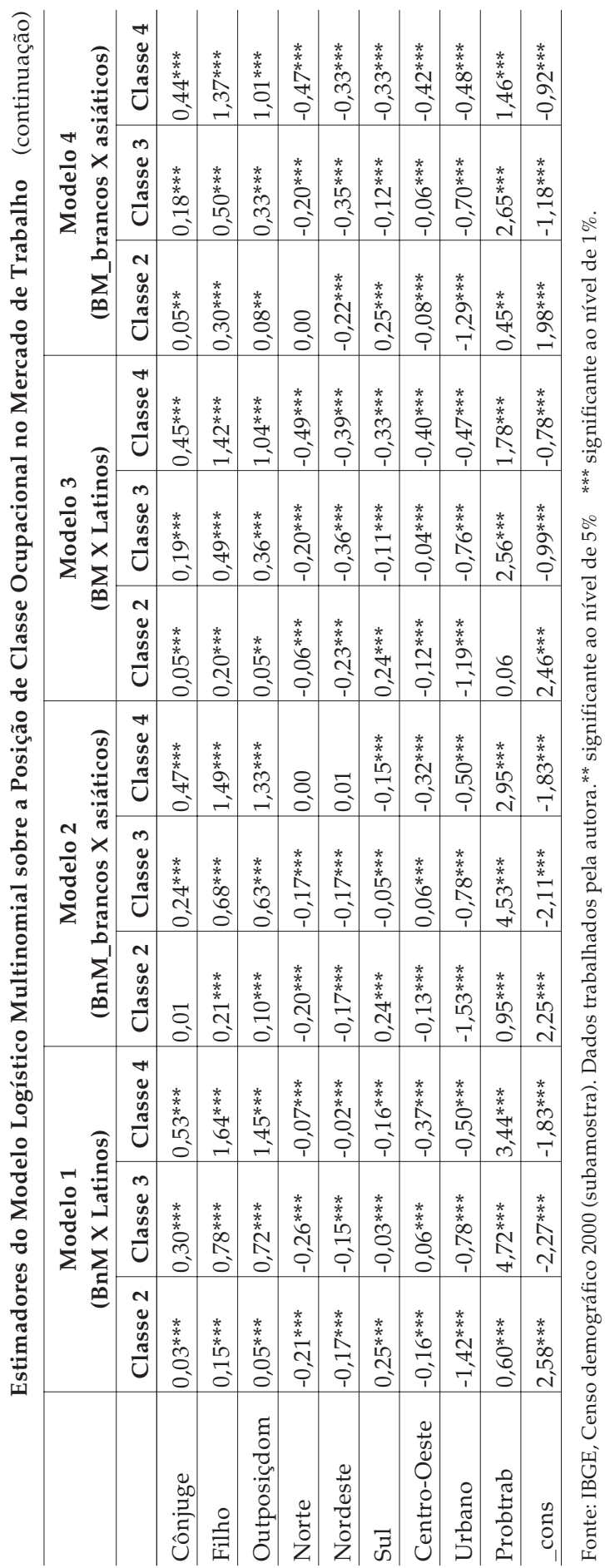


Desigualdade e Discriminação de Imigrantes Internacionais no Mercado...

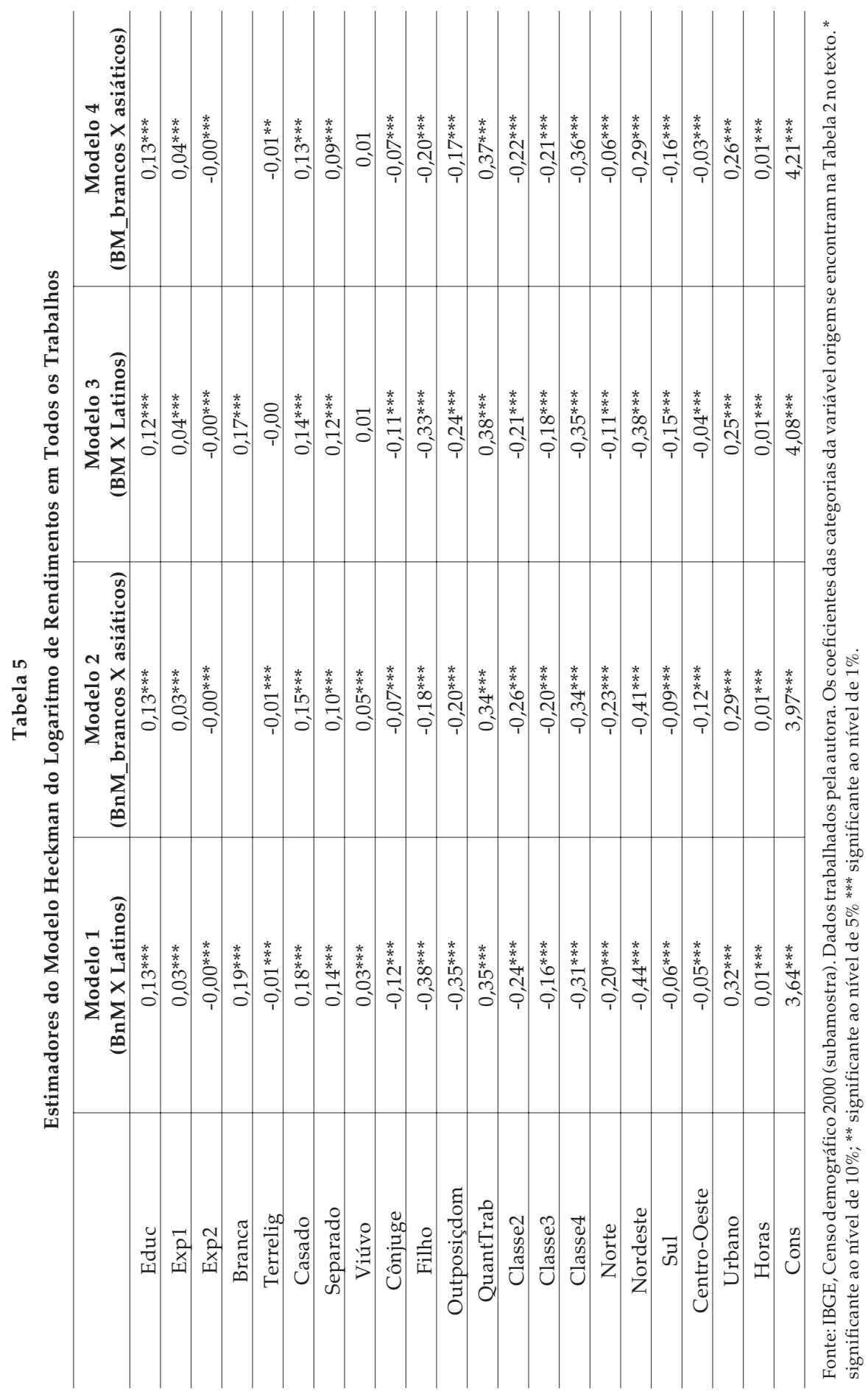




\section{ABSTRACT \\ Inequality and Discrimination against Foreign Immigrants in the Brazilian Work Market}

This study investigates the presence of discrimination in the Brazilian work market between foreign immigrants and Brazilians, all men, ranging from 25 to 60 years of age. The foreign immigrants, who were Korean, Chinese, Argentine, Bolivian, Chilean, Paraguayan, Peruvian, and Uruguayan nationals, were compared to native Brazilians. The data came from the Brazilian National Census, 2000. The findings were: 1) immigrant status is associated with higher class position and income; 2) ethnic/national origin has an impact on the individual's position in the work market; 3) immigrants' situation in the work market is heterogeneous; and iv) a situation of occupational and wage advantage does not mean that the individual does not suffer negative discrimination in the work market.

Key words: foreign immigrants; ethnic/national discrimination; class positions; income; migration

\section{RÉSUMÉ \\ Inégalité et Discrimination des Immigrants Étrangers sur le Marché du Travail au Brésil}

Dans cet article, on estime la présence d'inégalité et de discrimination sur le marché du travail entre Brésiliens et immigrants étrangers de sexe masculin entre 25 et 60 ans, provenant de Corée, Chine, Argentine, Bolivie, Chili, Paraguay, Pérou et Uruguay. Les données sont issues du recensement brésilien de l'an 2000. En voici les résultats: 1) être immigrant est un facteur qui détermine de façon positive la classe occupée et le revenu; 2) l'origine ethnique/nationale a une influence sur l'insertion de l'individu sur le marché du travail; 3) il y a une certaine hétérogénéité quant à la situation des immigrants sur le marché du travail; 4) un emploi et un salaire meilleurs n'empêchent pas l'individu de subir une discrimination sur le marché du travail.

Mots-clés: immigrants étrangers; discrimination ethnique/nationale; classe occupée; revenu; migration 